\title{
Engineering of activated carbon surface to enhance the catalytic activity of supported cobalt oxide nanoparticles in peroxymonosulfate activation
}

\begin{abstract}
Juan C. Espinosa, ${ }^{1}$ Premkumar Manickam-Periyaraman, ${ }^{1}$ Francisco Bernat-Quesada, ${ }^{1}$ Subramanian Sivanesan, ${ }^{2}$ Mercedes Álvaro, ${ }^{1}$ Hermenegildo García ${ }^{1,3, *}$ Sergio Navalón,,${ }^{1, *}$
\end{abstract} hgarcia@qim.upv.es; sernaol@doctor.upv.es

\begin{abstract}
${ }^{1}$ Departamento de Química and Instituto de Tecnología Química CSIC-UPV, Universitat Politècnica de València, Consejo Superior de Investigaciones Científicas, Av. de los Naranjos s/n, 46022 Valencia, Spain
\end{abstract}

${ }^{2}$ Department of Applied Science and Technology, Anna University, Sardar Patel road, 600025, Chennai, India

${ }^{3}$ Center of Excellence for Advanced Materials Research, King Abdulaziz University, Jeddah, Saudi Arabia

\section{Abstract}

Commercial activated carbon has been functionalized by chemical or thermal treatments to introduce surface oxygen functional groups able to anchor small cobalt nanoparticles with superior catalytic activity for peroxymonosulfate activation. The resulting activated carbon supports where characterized by combustion elemental analysis, Fouriertransformed infrared spectroscopy, Raman spectroscopy, isothermal $\mathrm{N}_{2}$ adsorption, temperature programmed desorption/mass spectrometry, X-ray diffraction and scanning electron microscopy. Activated carbon functionalization by nitric acid resulted the most appropriated method to provide a higher population of oxygenated functional groups able 
to anchor small cobalt nanoparticles. The catalytic activity of supported oxidized metal nanoparticles $(4.7 \pm 0.05 \mathrm{~nm})$ was higher than analogous non-oxidized cobalt nanoparticles $(2.9 \pm 0.14 \mathrm{~nm})$. The use of analogous supported oxidized iron or copper nanoparticles resulted in lower catalytic activity. Importantly, the supported oxidized cobalt nanoparticles at $0.2 \mathrm{wt} \%$ loading exhibit higher activity than benchmark catalysts such as unsupported $\mathrm{Co}_{3} \mathrm{O}_{4}$ solid or even homogeneous $\mathrm{Co}^{2+}$ ions. This high activity being a reflection of the relatively low estimated activation energies for peroxymonosulfate decomposition and phenol degradation with the values of about 30 and $32 \mathrm{~kJ} \mathrm{~mol}^{-1}$, respectively. The stability of the most active catalyst was assessed by performing eight consecutive uses without observing decrease of catalytic activity, neither metal leaching or metal nanoparticle aggregation. Turnover numbers/turnover frequencies values as high as $4 \cdot 10^{5} / 8 \cdot 10^{5} \mathrm{~h}^{-1}$ for peroxymonosulfate activation and $39 \cdot 10^{3} / 68 \cdot 10^{3} \mathrm{~h}^{-1}$ for phenol degradation at pH 7 and $20{ }^{\circ} \mathrm{C}$ have been estimated, respectively. Electron paramagnetic resonance measurements and selective quenching experiments revealed that the generated sulfate radicals from peroxymonosulfate rapidly are transformed in highly reactive hydroxyl radicals. In excellent agreement with previous reports, this work demonstrates the importance of an adequate activated carbon functionalization to obtain superior and stable catalysts for peroxymonosulfate activation.

Keywords: heterogeneous catalysis; advanced oxidation process; peroxymonosulfate reagent; cobalt oxide nanoparticles; functionalized activated carbon.

\section{Introduction}


Advanced oxidation processes (AOPs) are a class of chemical treatments for pollutant remediation in soil,[1, 2] water[3-5] and air.[6] The aim of AOPs is the generation of highly aggressive radicals such as $\mathrm{HO}^{\circ}, \mathrm{HOO}^{*}$ or $\mathrm{SO}_{4}{ }^{-}$that able to attack virtually any organic contaminant in aqueous media triggering their aerobic degradation and, eventually, their mineralization.[5, 7] In the field of waste water treatments AOPs are frequently employed to degrade recalcitrant, toxic and/or non-biodegradable compounds that cannot be treated using conventional biological water treatments.[8] One of the AOPs with easiest implementation is the (photo)Fenton reaction that employs $\mathrm{Fe}(\mathrm{II})$ salts and $\mathrm{H}_{2} \mathrm{O}_{2}$ at acidic $\mathrm{pH}(\sim 3)$ to generate hydroxyl radicals from $\mathrm{H}_{2} \mathrm{O}_{2}$.[3, 5] One of the main drawbacks, however, of the (photo)Fenton reaction is the need of acidic $\mathrm{pH}$ values in order to avoid iron precipitation. The use of acidic $\mathrm{pH}$ values is also beneficial for $\mathrm{H}_{2} \mathrm{O}_{2}$ stability since at basic $\mathrm{pH}$ values it decomposes spuriously to $\mathrm{O}_{2}$ without generating $\mathrm{HO}^{\circ}$ radicals. An alternative, $\mathrm{AOP}$ treatment that is less $\mathrm{pH}$ dependent based on the Co(II) ions as homogeneous catalyst to activate peroxymonosulfate (PMS) to generate sulfate radicals $\left(\mathrm{SO}_{4}{ }^{-}\right) \cdot[9-11]$ It is worth to mention that in comparison to $\mathrm{Fe}(\mathrm{II}), \mathrm{Co}(\mathrm{II})$ ions remain soluble in aqueous solutions at $\mathrm{pH}$ values below 9.4.[9, 10] Importantly, PMS can operate efficiently at higher $\mathrm{pH}$ values including neutral aqueous solutions.[9] Sulfate radicals have a similar oxidation potential (about 2.5-3.1 V vs NHE) as hydroxyl radicals, but with higher half-life period about (30-40 $\mu$ s vs $1 \mu$ s).[10]

Regardless the good pollutant degradation efficiencies achieved using the commented homogeneous AOPs under optimal reaction conditions, practical applications are limited due to the need of removal from the treated waters of dissolved transition metals employed in the process to avoid negative environmental impacts and risks for the human health.[4, 5, 10,11] Cobalt concentration is typically limited in drinking water to values lower than $50 \mu \mathrm{g} \mathrm{L}^{-1}$.[11] The removal of the transition metal ions is generally 
carried out by precipitation with the disadvantage of needing further addition of chemicals and the subsequent sludge formation. Furthermore, in order to accomplish the water quality regulations, the removal of these transition metal ions should be done at levels below micrograms per liter.[12] These reasons, strongly limit the practical applications of homogenous AOPs using transition metals other than Fe.

In order to solve these problems, heterogeneous catalytic AOPs have been developed.[10, 11, 13-15] Frequently, metal or metal oxide NPs are supported on a high surface area insoluble material, allowing the easy recovery and immobilization of the transition metal.[10, 11, 13, 14] In this context, insoluble cobalt oxides[9, 16] or cobalt and cobalt oxides deposited on supports including metal oxides (i.e. $\mathrm{Al}_{2} \mathrm{O}_{3}, \mathrm{SiO}_{2}$, $\mathrm{TiO}_{2}$ ),[17-19] carbonaceous materials such as activated carbon[20] or carbon aerogels[21], cobalt exchanged zeolites[22] or even MOFs[23] have been reported as heterogeneous catalysts for PMS activation.[10, 11]

However, in spite of the advances done in the field of heterogeneous cobalt-based catalysts for PMS activation, there still remain some challenges to increase further the activity and stability of the catalysts. Among these challenges, those dealing with the preparation of small metal NPs and their stabilization through a strong interaction with the support are crucial to obtain highly efficient and stable materials.[10, 11, 24]

The present work shows the importance of an adequate surface functionalization of active carbon to support small, active and stable cobalt oxide NPs able to activate PMS. In this way, efficient heterogeneous catalyst promoting phenol degradation as aqueous model pollutant has been obtained. The highest activity has been determined for the catalyst having the smallest cobalt oxide NPs. Thus, it will be shown that commercial active carbon functionalized by $\mathrm{HNO}_{3}$ acid treatment under optimal conditions is a 
suitable support to deposit small cobalt oxide NPs with enhanced catalytic activity. In contrast, active carbon functionalization with a controlled thermal oxidation results in a catalyst with lower activity due to the bigger cobalt oxide NPs are formed. The influence of the cobalt oxidation state on the resulting catalytic activity has been also evaluated, observing that cobalt oxide NPs are more active than reduced cobalt. Importantly, the active carbon supported cobalt oxide catalyst can be reused at least eight times at neutral $\mathrm{pH}$ and room temperature without observing neither loss of catalytic activity nor metal leaching. Selective quenching experiments and EPR spectroscopic study prove that PMS activation using the supported cobalt oxide catalyst generates hydroxyl radicals.

\section{Experimental section}

\subsection{Materials}

Oxone ${ }^{\circledR}$ (potassium peroxymonosulfate, PMS) $\left(\mathrm{KHSO}_{5} \cdot 1 / 2 \mathrm{KHSO}_{4} \cdot 1 / 2 \mathrm{~K}_{2} \mathrm{SO}_{4}, \mathrm{MW}\right.$ 307.38), commercial active carbon (AC, Norit SX Ultra, ref. 53663), $\mathrm{Co}\left(\mathrm{NO}_{3}\right)_{2} \cdot 6 \mathrm{H}_{2} \mathrm{O}$ (>99.999\%), $\mathrm{Co}_{3} \mathrm{O}_{4}$ nanopowder ( $\left.<50 \mathrm{~nm}\right)$ and phenol (>99.5\%) were supplied by SigmaAldrich. Other reactants or solvents employed were analytical or HPLC grade and they were also supplied by Sigma-Aldrich.

\subsection{Methods}

Commercial activated carbon functionalization by nitric acid. Briefly, commercial AC (1 g) was dispersed in concentrated nitric acid (65 \%) in a round-bottom flask and the system heated at $83{ }^{\circ} \mathrm{C}$ for $24 \mathrm{~h}$. Then, the solid sample was submitted to several consecutive centrifugation-redispersion washings with Milli-Q water until the $\mathrm{pH}$ of the supernatant was neutral. Finally, the solid was dried in an oven at $100{ }^{\circ} \mathrm{C}$ for $24 \mathrm{~h}$ and the sample labelled as ACN. 
AC functionalization by thermal treatment. Briefly, commercial AC (200 mg) was heated $\left(7^{\circ} \mathrm{C} \mathrm{min}^{-1}\right)$ in an oven under static air up to $420{ }^{\circ} \mathrm{C}$ and, this temperature was maintained for $2 \mathrm{~h}$. Then, the sample was cooled down to room temperature and labelled as ACT.

Deposition of cobalt NPs on the AC supports (Co/ACs). Cobalt NPs were supported on commercial AC, ACN and ACT solids by using the polyol method.[25] Briefly, the corresponding active carbon support (200 mg) was suspended in ethylene glycol (80 mL), sonicated for $20 \mathrm{~min}$. Then, the appropriate amount of cobalt salt dissolved in water (1 $\mathrm{mL}$ ) was added to the suspension to achieve the required metal loading ( 0.2 or $1 \mathrm{wt} \%$ ) and the system was heated at $85^{\circ} \mathrm{C}$ for $4 \mathrm{~h}$. After cooling the system at room temperature, the solid was recovered by centrifugation and washed by four consecutive centrifugationredispersion cycles using consecutively ethanol and water as solvents. The catalysts were freeze-dried and labelled as $\mathrm{Co} / \mathrm{AC}, \mathrm{Co} / \mathrm{ACN}$ or $\mathrm{Co} / \mathrm{ACT}$. These solid samples were further oxidized in an oven under static air at $180{ }^{\circ} \mathrm{C}$ for $2 \mathrm{~h}$ and the samples labelled as $\mathrm{Co}_{\text {ox }} / \mathrm{AC}, \mathrm{Co}_{\text {ox }} / \mathrm{ACN}$ or $\mathrm{Co}_{\text {ox }} / \mathrm{ACT}$. Analogous $\mathrm{Fe}_{\text {ox }}$ or $\mathrm{Cu}_{\text {ox }}$ supported on ACN catalysts were also prepared using this methodology employing $\mathrm{Fe}\left(\mathrm{NO}_{3}\right) \cdot 7 \mathrm{H}_{2} \mathrm{O}$ or $\mathrm{Cu}\left(\mathrm{NO}_{3}\right)_{2}$ salts as metal precursors.

Unsupported cobalt oxide NPs were prepared by reduction of an aqueous solution (25 $\mathrm{mL}$ ) containing cobalt nitrate hexahydrate $\left(10 \mathrm{mg} \mathrm{mL}^{-1}\right)$ using 10 -fold excess of $\mathrm{NaBH}_{4}$ as reducing agent. The obtained solid was recovered by filtration and washed with distillated water (500 mL). Finally, the solid was placed in an oven and heated at $180{ }^{\circ} \mathrm{C}$ for $2 \mathrm{~h}$.

\subsection{Catalyst and activated carbon characterization}


Powder X-ray diffractograms were collected by using a Philips X-Pert diffractometer equipped with a graphite monochromator operating at $40 \mathrm{kV}$ and $45 \mathrm{~mA}$ that employed Ni-filtered CuKa radiation. FTIR spectra were measured by using a Bruker Tensor 27 FT-ATR instrument. A Perkin Elmer CHNOS analyzer was employed for combustion elemental analysis. Temperature-programmed desorption (TPD) coupled to a mass-spectrometer (TPD-MS) analyses of the active carbons (100 mg) were carried out in a Micrometer II 2920 connected to a quadrupolar mass-spectrometer measurements were carried out by heating the sample from room temperature to $900{ }^{\circ} \mathrm{C}$ at $10{ }^{\circ} \mathrm{C} \mathrm{min}{ }^{-1}$. X-ray photoelectron spectroscopy (XPS) measurements were performed on a SPECS spectrometer with an MCD-9 detector using a monochromatic $\mathrm{Al}(\mathrm{K} \alpha=1486.6 \mathrm{eV}) \mathrm{X}$ ray source. CASA software has been employed for spectra deconvolution setting at 284.4 $\mathrm{eV}[26]$ the C1s peak as reference. Isothermal $\mathrm{N}_{2}$ adsorption measurements were carried out using a ASAP 2010 Micrometrics apparatus. The metal loading (Co, Fe or Cu) on the ACs was determined by inductively coupled plasma combined with optical atomic emission spectroscopy detection (ICP-OES). Cobalt leaching was assessed by ICP-OES in the liquid reaction phase after removal the solid catalyst at the end of the reaction. A JEOL JEM-2100F instrument operating at $200 \mathrm{~kW}$ under dark-field scanning transmission electron microscopy (DF-STEM) was employed for metal particle size estimation measuring the dimensions of more than 200 particles. Microanalysis of the particles was performed by using an EDX detector (Oxford instrument) coupled to the DF-STEM measurements.

\subsection{Catalytic activity and reaction analysis}

Catalytic experiments were carried out at least in duplicate. Briefly, the required amount of catalyst was added to a round-bottomed flask (500 mL) containing an aqueous phenol solution (100 mL; $\left.100 \mathrm{mg} \mathrm{L}^{-1} ; 1.06 \mathrm{mM}\right)$, and the system sonicated for $20 \mathrm{~min}$. 
The initial $\mathrm{pH}$ of the suspension was adjusted to the required value using aqueous solutions of $\mathrm{HNO}_{3}(0.1 \mathrm{M})$ or $\mathrm{NaOH}(0.1 \mathrm{M})$. If necessary the flask was placed in a heaton block and heated at the required temperature. The corresponding amount of PMS dissolved in water $(1 \mathrm{~mL})$ at the corresponding $\mathrm{pH}$ value was added. During the course of the reaction the $\mathrm{pH}$ frequently was adjusted at the required value by addition of $\mathrm{HNO}_{3}$ (0.1 M) or $\mathrm{NaOH}(0.1 \mathrm{M})$.

In order to study the reusability of the catalyst, the solid was recovered at the end of the reaction by filtration using a nylon membrane $(0.2 \mu \mathrm{m})$, washed with a $\mathrm{NaOH}$ aqueous solution ( $\mathrm{pH}$ 10) and then Milli-Q water to remove possible adsorbed organic or inorganic substances. Then, the catalyst was employed in a new catalytic cycle.

Productivity tests were carried out using large amount of phenol $\left(10 \mathrm{~g} \mathrm{~L}^{-1} ; 106.4\right.$ $\mathrm{mM}$ ) and PMS (280 $\mathrm{g} \mathrm{L}^{-1} ; 911 \mathrm{mM}$ ) with respect to the catalyst (200 $\mathrm{mg} \mathrm{L}^{-1} ; 0.0067 \mathrm{mM}$ of supported cobalt) at $\mathrm{pH} 7$ and $20^{\circ} \mathrm{C}$. The catalyst was reused under these concentrations several times as previously described.

Analysis of phenol, catechol, hydroquinone and p-benzoquinone. Previously filtered reaction aliquots (Nylon filter $0.2 \mu \mathrm{m}$ ) were analyzed by reverse-phase liquid chromatography. A Kromasil-C18 column was employed as stationary phase. Elution was carried out under isocratic conditions (69:30:1 vol\% $\mathrm{H}_{2} \mathrm{O} / \mathrm{CH}_{3} \mathrm{CN} / \mathrm{CH}_{3} \mathrm{COOH}$ ). The system used a photodiode array as detector. The samples from the productivity test were diluted 100-fold in Milli-Q water before analysis.

TOC analysis. A High-TOC Elementar II analyzer was employed for TOC measurements of previously filtered aqueous reaction aliquots. The method is based on the complete combustion of the organic matter present in the aqueous sample at $950{ }^{\circ} \mathrm{C}$ catalyzed by Pt and quantification of evolved $\mathrm{CO}_{2}$ gas by quantitative IR spectroscopy. 
PMS measurements. PMS concentration was measured using a spectrophotometric method.[27] Briefly, a previously filtered reaction aliquot $(0.5 \mathrm{~mL})$ was diluted with Milli-Q water (4.5 mL), an excess solution of KI ( $0.5 \mathrm{~mL}, 2 \mathrm{mg} / \mathrm{mL})$ added and, then, the solution absorbance recorded at $360 \mathrm{~nm}$.

EPR measurements. EPR spectra were recorded using phenyl tert-butil nitrone (PBN) as spin trapping agent under the following reaction conditions: catalyst (200 mg $\mathrm{L}^{-1}, 0.0067$ mM of supported cobalt), PBN (1000 $\mathrm{mg} \mathrm{L}^{-1}$ ), PMS to DMPO molar ratio 1, pH 7, reaction time (5 min). Previously filtered $(0.2 \mu \mathrm{m})$ and nitrogen-purged aliquots were measured in a Bruker EMX spectrometer using the following typical settings: frequency 9.803 GHz, sweep width $3489.9 \mathrm{G}$, time constant 40.95 ms, modulation frequency 100 kHz, modulation width $1 \mathrm{G}$, and microwave power $19.92 \mathrm{~mW}$.

Radical quenching experiments. Selective hydroxyl radical quenching experiments were carried out under the following conditions: Catalyst (200 mg L-1; $0.0067 \mathrm{mM}$ ), phenol (100 mg L ${ }^{-1}$ ), PMS (2800 mg L ${ }^{-1}$; $9.1 \mathrm{mM}$ ), air atmosphere, $\mathrm{pH}$ 4, DMSO to PMS molar ratio of 10.

\section{Results and discussion}

\subsection{Support preparation and characterization}

The use of carbonaceous materials as metal NP supports is one of the main areas of research in heterogeneous catalysis.[14] In this sense, some examples have shown that the chemical composition, the textural properties and the groups on the surface of the carbonaceous materials determine the resulting metal particle size distribution and, therefore, the catalytic activity.[24] With these precedents in mind, our work starts with the functionalization of commercial activated carbon (Norit), referred as AC, by chemical[28, 29] or thermal oxidative treatment.[30] The chemical functionalization of 
the activated carbon consists in a liquid phase oxidation of AC by nitric acid resulting in a sample labeled as ACN. The thermal functionalization method consists in submitting AC to an aerobic oxidation in static air at $420^{\circ} \mathrm{C}$ in an oven. This sample is labelled as ACT. The three samples (AC, ACT and ACN) were characterized by combustion elemental analysis, FT-IR and Raman spectroscopy, isothermal $\mathrm{N}_{2}$ adsorption, XPS, TPD-MS, XRD and SEM.

Elemental analysis data show that the oxidative treatment of $\mathrm{AC}$ using $\mathrm{HNO}_{3}$ is more effective to increase the oxygen content of the carbon than that based on the thermal treatment (Table 1). In particular, the chemical treatment using $\mathrm{HNO}_{3}$ affords a high decrease of carbon content together with a concomitant increase in oxygen content compared to ACT sample. A small increase of elemental nitrogen in the ACN sample (1.0 wt\%) respect to the commercial AC sample (0.3 wt\%) was also observed and attributed to the functionalization with nitrogen oxide species.[28, 29] Isothermal $\mathrm{N}_{2}$ adsorption (Figures S1-S3) of the ACs reveals that, regardless the observed variations respect to AC, the resulting carbonaceous samples exhibits surface areas and pore volumes higher than $700 \mathrm{~m}^{2} \mathrm{~g}^{-1}$ and $0.26 \mathrm{~cm}^{3} \mathrm{~g}^{-1}$, respectively. The lower values observed for the ACN sample can be attributed to space required to accommodate a large density of oxygenated functional groups within the pores of the solid.

\begin{tabular}{|c|c|c|c|c|c|}
\hline & C (\%) & $\begin{array}{l}\mathrm{C} / \mathrm{H} \text { molar } \\
\text { ratio (\%) }\end{array}$ & $\begin{array}{l}\mathrm{C} / \mathrm{O} \text { molar } \\
\text { ratio (\%) }\end{array}$ & $\begin{array}{l}\text { BET surface } \\
\text { area }\left(\mathrm{m}^{2} \mathrm{~g}^{-1}\right)\end{array}$ & $\begin{array}{l}\text { Pore volumen } \\
\left(\mathrm{cm}^{3} \mathrm{~g}^{-1}\right)\end{array}$ \\
\hline $\mathrm{AC}$ & 76.7 & 14.3 & 4.5 & 880 & 0.32 \\
\hline $\mathrm{ACN}$ & 58.3 & 5.4 & 2.0 & 710 & 0.26 \\
\hline ACT & 74.3 & 14.9 & 4.0 & 1040 & 0.35 \\
\hline
\end{tabular}


Raman spectroscopy of the three AC samples shows the characteristic vibrations modes due to the stretching of $\mathrm{sp}^{2}$ carbons at $1597 \mathrm{~cm}^{-1}$ ( $\mathrm{G}$ band), occurrence of disordered structure at $1317 \mathrm{~cm}^{-1}$ (D band) and the stacking of the $\mathrm{sp}^{2}$ network layers at $2567 \mathrm{~cm}^{-1}$ (2D band) (Figure 1a).[31] Functionalization of AC sample by thermal or chemical methods results in an increase of the defect population as revealed by the increase in the intensity of D respect to $G$ band.[31] FT-IR spectroscopy of the functionalized activated carbons shows an intensity increase of the peaks appearing at $1725 \mathrm{~cm}^{-1}$ and $1160 \mathrm{~cm}^{-1}$ attributable $\mathrm{C}=\mathrm{O}$ and $\mathrm{C}-\mathrm{O}$ stretching bands, respectively, as well as the band appearing at $1560 \mathrm{~cm}^{-1}$ corresponding to the presence of conjugated unsaturated $\mathrm{C}=\mathrm{C}$ bonds (Figure $1 \mathrm{~b}$ )[29, 32]. All these observations are in agreement with the increase of oxygen content observed by elemental analysis.
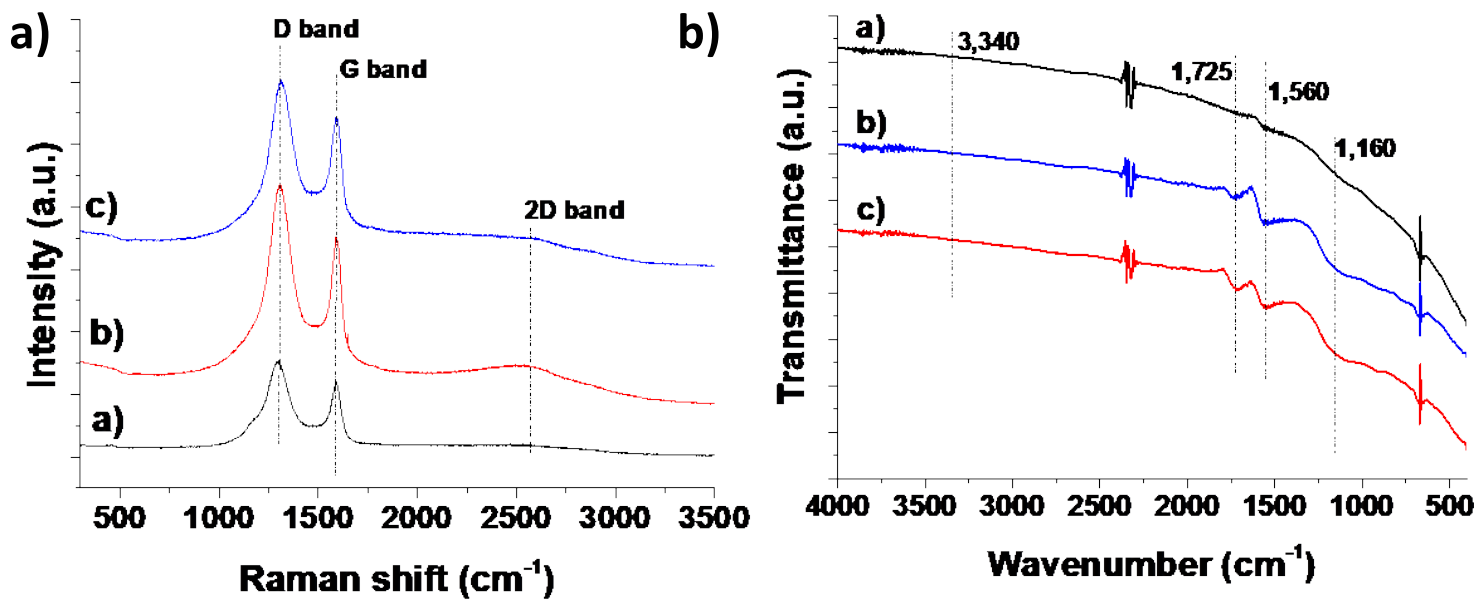

Figure 1. Raman (a) and FT-IR (b) spectra of AC (a), ACT (b) and ACN (c) materials.

The three ACs were further analyzed by TPD (Figure 2a) and TPD-MS (Figure 2b-c) measurements under inert atmosphere. In particular, the TPD-MS allows identification by mass spectrometry of $\mathrm{H}_{2} \mathrm{O}(\mathrm{m} / \mathrm{z} 18)$, $\mathrm{CO}(\mathrm{m} / \mathrm{z} 28)$ and $\mathrm{CO}_{2}(\mathrm{~m} / \mathrm{z}$ 44).[29] AC functionalization by $\mathrm{HNO}_{3}$ resulted in the introduction of a large variety of oxygen 
functional groups including carboxylic acids, lactones, anhydrides, phenolic, carbonyls, ether and quinone among other possible.[29, 32] In the case of AC functionalization by an oxidative thermal treatment at $420{ }^{\circ} \mathrm{C}$ the resulting ACT solid results mainly functionalized with phenol, carbonyl and quinone moieties, probably because most of carboxylic acid moieties are unstable at the temperatures of the thermal treatment (420 $\left.{ }^{\circ} \mathrm{C}\right)$ or they are not formed.[29, 32]

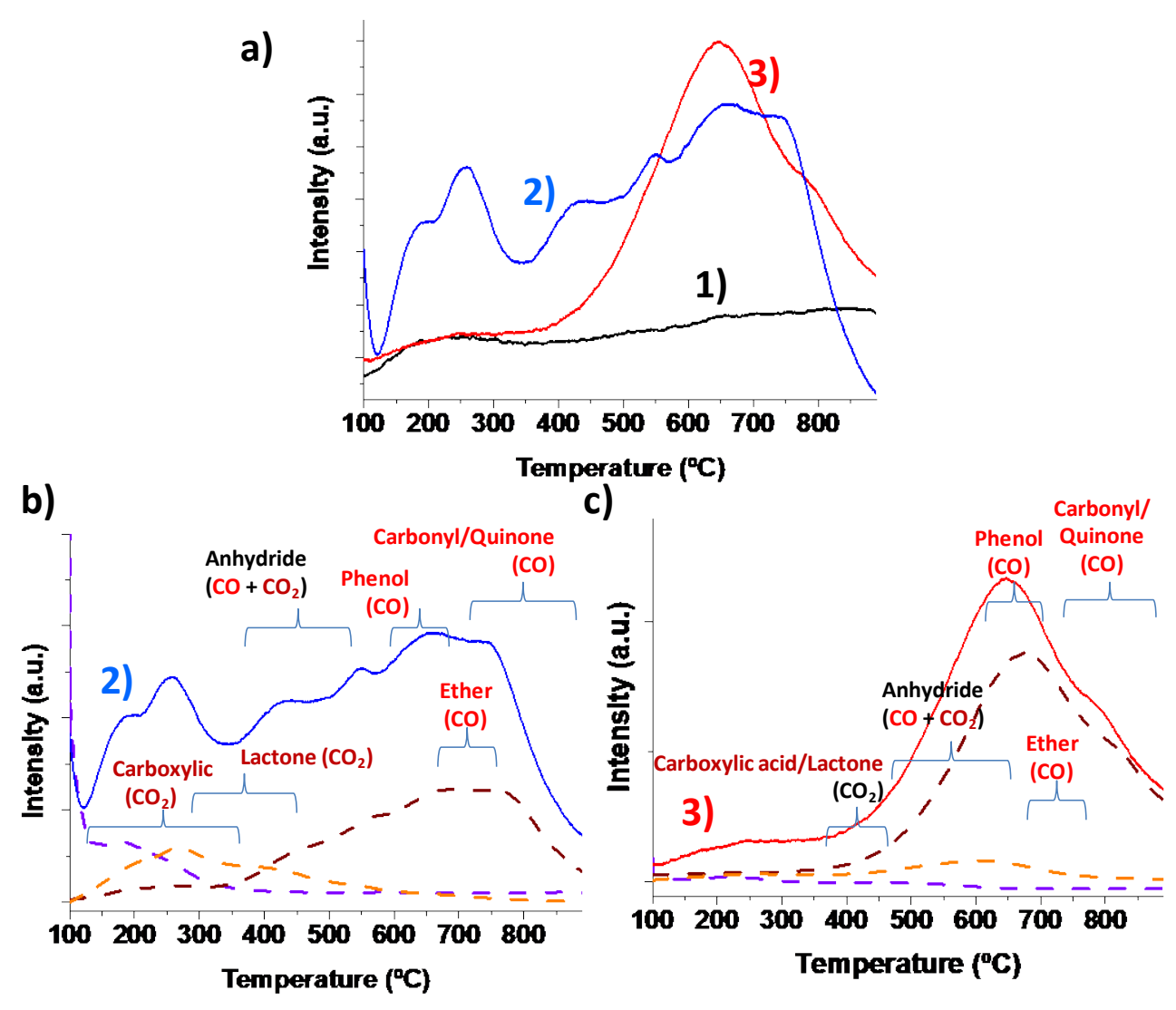

Figure 2. TPD (a) and TPD-MS (b, c) of commercial AC (1, black line), ACN (2, blue line) and ACT (3, red line). Legend: $\mathrm{H}_{2} \mathrm{O}$ (violet dash line), $\mathrm{CO}_{2}$ (orange dash line) and CO (brown dash line).

The surface of the carbonaceous materials was evaluated by XPS analyses (Figure 3 and S5).[29] As expected, AC oxidation by chemical or thermal treatments resulted in a shift of the C1s signals at higher binding energies indicating the oxidation of the carbon 
surface. In the case of O1s, an increase of the signal intensity for ACN sample or a shift to higher binding energies in the case of ACT agree with a different level of oxidation of AC sample, depending on the treatment. These observations agree with the generation of different oxygen functional groups. The oxidation of the AC by chemical or thermal treatment as well as the increase of acidic oxygen functional groups was verified by measuring the $\mathrm{pH}$ of aqueous suspensions of AC, ACT and ACN (10 mg mL $\left.\mathrm{mL}^{-1}\right)$ corresponding to the values of $6.5,4.8$ and 3.6, respectively.
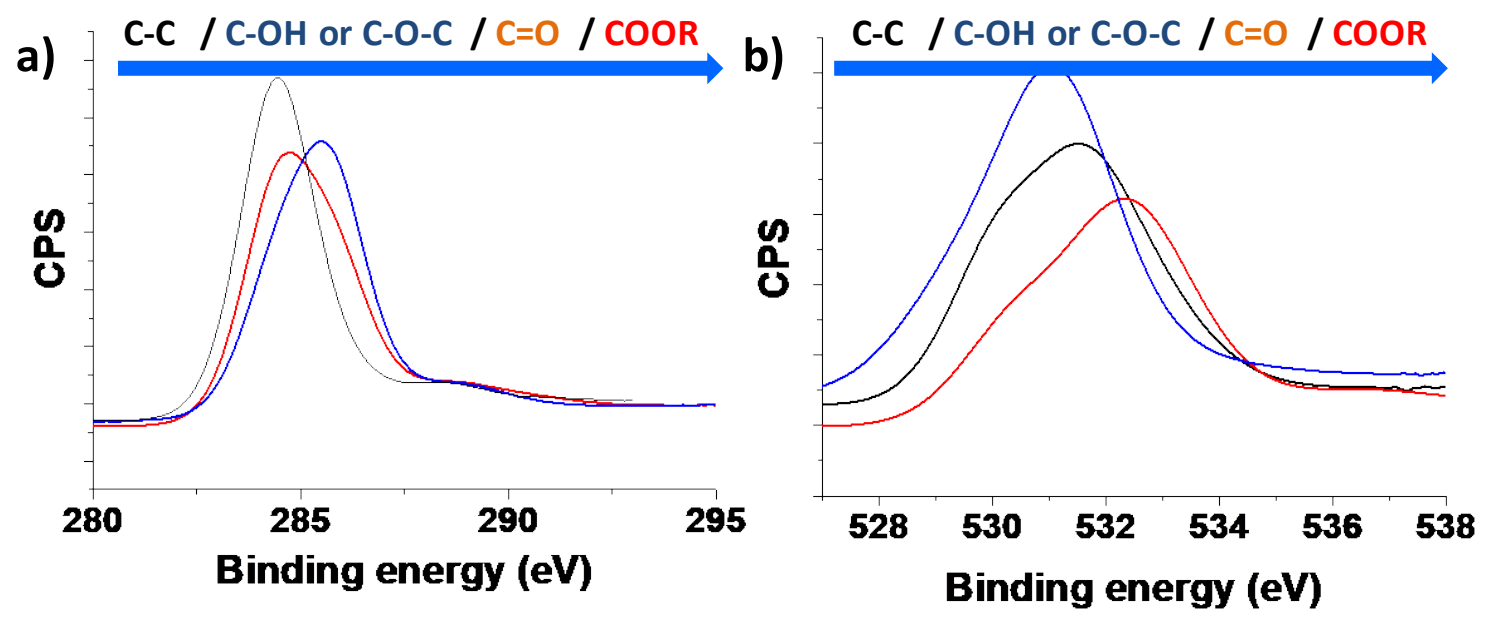

Figure 3. XPS C1s (a) and O1s (b) of AC (black), ACT (red) and ACN (blue).

PXRD of the ACs samples reveals that the structure is maintained after the functionalization of the commercial AC. The diffractograms show the two main characteristic broad bands of activated carbons appearing at around $2 \theta 23$ and $43^{\circ}$ associated with the diffraction from the 002 and 100/101 planes in graphite, respectively (Figure S4).[33] SEM images show that the morphological structure is somehow preserved, but as the functionalization degree increases (ACN $>A C T$ ) the roughness of the AC surface increases (Figure S6).

\subsection{Metal supported on ACs}


Deposition of cobalt NPs on the three activated carbons (AC, ACT and ACN) was carried out using the well-known polyol method.[25, 34] In order to study the influence of the cobalt oxidation state on the catalytic activity for PMS activation, the Co NP supported on AC samples were further submitted to an aerobic oxidation under static air at $180{ }^{\circ} \mathrm{C}$ for $2 \mathrm{~h}$. Several works have shown the influence of the cobalt oxidation state on PMS activation. ${ }^{10,11}$ Table 2 summarizes the list of catalysts employed in the present work, including metal loading, average particle size distribution, standard deviation obtained from TEM measurements (Figure 4, S7-S9) and the initial reaction rates for PMS activation and phenol degradation.

\begin{tabular}{|c|c|c|c|c|c|}
\hline Entry & Catalyst & $\begin{array}{l}\text { Metal } \\
\text { loading } \\
\text { (wt\%) }\end{array}$ & $\begin{array}{l}\text { Average metal particle size } \\
\text { and standard deviation (nm) }\end{array}$ & $\begin{array}{l}\text { ro_PMS } \\
\left(\mathrm{mM} \mathrm{h}^{-1}\right)\end{array}$ & $\begin{array}{l}\text { ro_phenol } \\
\left(\mathrm{mM} \mathrm{h}^{-1}\right)\end{array}$ \\
\hline 1 & $\mathrm{Co} / \mathrm{ACN}$ & 0.2 & $2.9 \pm 0.14$ & 16.07 & 2.44 \\
\hline 2 & $\mathrm{Co} / \mathrm{ACT}$ & 0.2 & $3.3 \pm 0.17$ & 10.55 & 3.38 \\
\hline 3 & $\mathrm{Co} / \mathrm{AC}$ & 0.2 & $4.1 \pm 0.23$ & 8.91 & 3.94 \\
\hline 4 & $\mathrm{Co}_{\text {ox }} / \mathrm{ACN}$ & 0.2 & $4.7 \pm 0.05$ & 23.84 & 4.52 \\
\hline 5 & $\mathrm{Co}_{\text {ox }} / \mathrm{ACT}$ & 0.2 & $7.9 \pm 0.26$ & 21.22 & 5.25 \\
\hline 6 & $\mathrm{Coox} / \mathrm{AC}$ & 0.2 & $9.1 \pm 0.25$ & 12.51 & 6.40 \\
\hline 7 & $\mathrm{Co}_{\text {ox }} / \mathrm{ACN}$ & 1.0 & $5.8 \pm 0.24$ & 9.12 & 1.66 \\
\hline 8 & $\mathrm{Fe}_{\text {ox }} / \mathrm{ACN}$ & 1.0 & $5.6 \pm 0.17$ & 3.91 & 0.55 \\
\hline 9 & $\mathrm{Cu}_{\text {ox }} / \mathrm{ACN}$ & 1.0 & $6.3 \pm 0.25$ & 2.93 & 0.47 \\
\hline
\end{tabular}

Selected DF-STEM images and metal particle size distribution histograms are shown in Figure 4. Regardless the oxidation state of cobalt NPs, the smallest average cobalt particle size and standard deviation at the same metal loading is obtained using ACN as support (Table 2). Thus, it can be speculated that the presence of a high 
population of oxygen functional groups in ACN support is beneficial to support small metal NPs. As expected, the aerobic oxidation of cobalt NPs supported on ACs (Figure S7) resulted in an increase of the cobalt oxide average particle size of about 2-3 nm (Table 2 and Figure S8). Using ACN as support it was observed that an increase of the cobalt oxide content from 0.2 to $1.0 \mathrm{wt} \%$ resulted in an increase of both particle size distribution and standard deviation (entries 4 and 7 in Table 2 and Figure S9). Analogous catalysts based on iron and copper oxides supported on ACN were also prepared (entries 8 and 9 in Table 2 and Figure S9) to compare their catalytic activity with that of cobalt based materials. Formation of cobalt NPs was confirmed by EDX analyses of different points (Figure S10a), areas (Figure S10b) and mapping analyses (Figure 4). In contrast to the small cobalt oxide NPs obtained on the different carbonaceous materials, large particles ( $>200 \mathrm{~nm}$ ) were obtained when the preparation of cobalt oxide was performed without the use of any support (Figure S11).
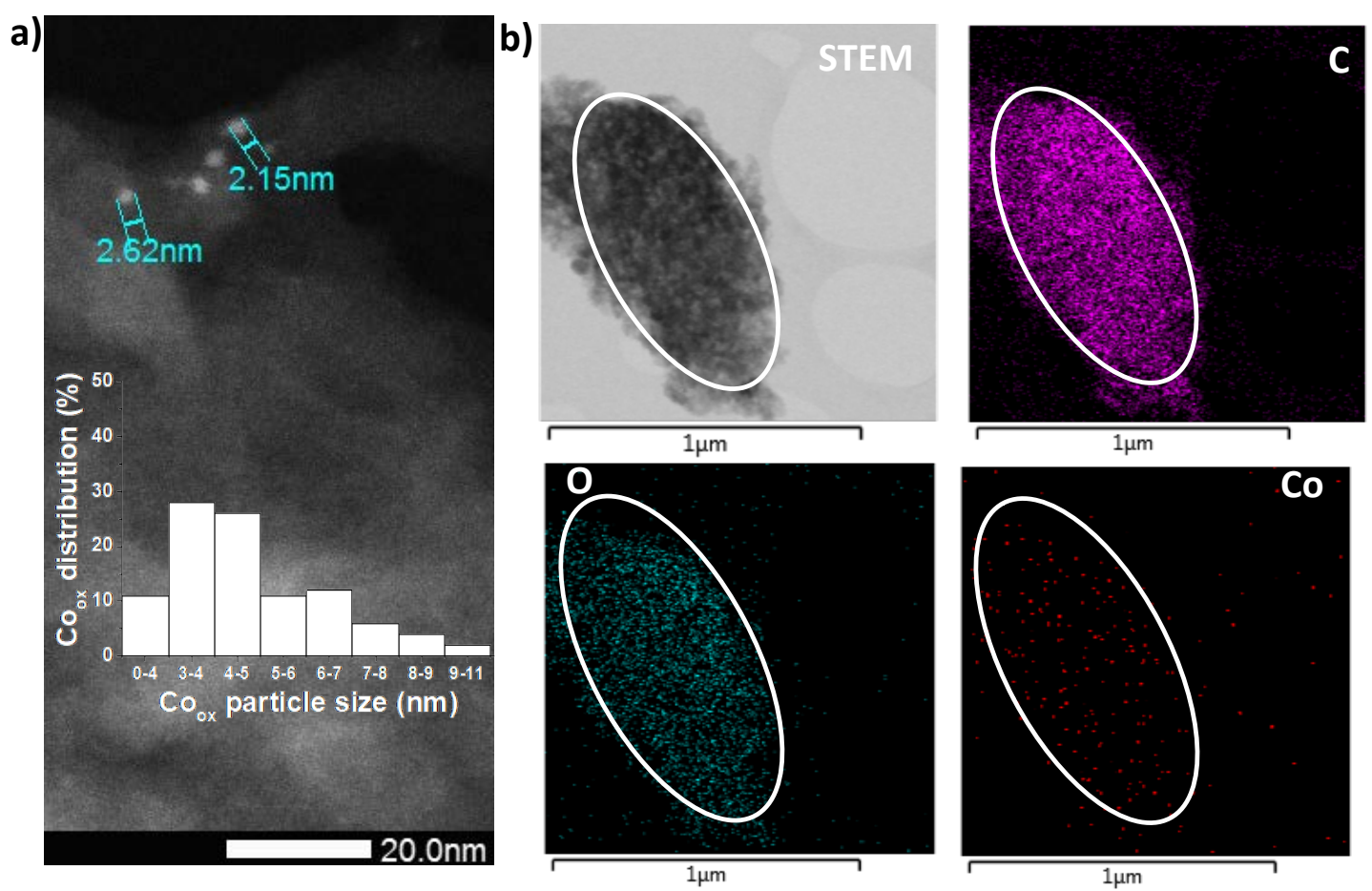
Figure 4. a) DF-STEM image and cobalt particle distribution of Coox $(0.2 w t \%) / A C N ;$ b) STEM image and element mapping microanalyses of $\mathrm{Co}_{\text {ox }}(0.2 \mathrm{wt} \%) / \mathrm{ACN}$. The inset in panel a shows the particle size distribution of cobalt oxide in Coox $(0.2 \mathrm{wt} \%) / \mathrm{ACN}$

XPS analysis was employed to get some insights about the cobalt oxidation state of the prepared catalysts. As it will be shown below $\mathrm{Co}_{\text {ox }} / \mathrm{ACN}$ is the most active catalyst for PMS activation. As expected the aerobic oxidation of the Co(0.2wt $\%) / A C N$ (Figure 5a1) solid results in the oxidation of Co NPs in the Coox $(0.2 \mathrm{wt} \%) / \mathrm{ACN}$ solid to Co(II) and Co(III) species (Figure 5a2). These oxidized Co(II / III) species are similar to those observed in the case of commercial $\mathrm{Co}_{3} \mathrm{O}_{4}$ solid (Figure 5a3) and as-made $\mathrm{Co}_{\text {ox }}$ solid (Figure 5a3). For the $\operatorname{Coox}(0.2 \mathrm{wt} \%) / \mathrm{ACN}$ sample, Figure $5 \mathrm{~b}$ shows the deconvoluted peaks at around 779.7 and $781.4 \mathrm{eV}$ attributable to the $\mathrm{Co}^{3+} 2 \mathrm{p}_{3 / 2}$ and $\mathrm{Co}^{2+} 2 \mathrm{p}_{3 / 2}$, respectively. The accompanying $2 \mathrm{p}_{1 / 2}$ spin-orbit component for $\mathrm{Co}^{3+}$ and $\mathrm{Co}^{2+}$ appear at 794.8 and $796.8 \mathrm{eV}$, respectively. The energy difference between Co 2p3/2 and Co 2p1/2 peaks is approximately $15 \mathrm{eV}$. Two $\mathrm{Co}^{2+}$ satellite peaks at 786.3 and $804.8 \mathrm{eV}$ are also observed. Similar deconvolution in various cobalt species is obtained for the commercial $\mathrm{Co}_{3} \mathrm{O}_{4}$ or as-made $\mathrm{Co}_{\text {ox }}$ solids (Figure S12). These XPS results agree with the presence of cobalt NPs in the form of $\mathrm{Co}_{3} \mathrm{O}_{4}$ and/or CoO.[35-38] Similarly, the XPS spectra of $\mathrm{Fe}_{\text {ox }} / \mathrm{ACN}$ and $\mathrm{Cu}_{\mathrm{ox}} / \mathrm{ACN}$ samples reveal the presence of oxidized metal species in the form of $\mathrm{Fe}^{3+} / \mathrm{Fe}^{2+}$ or $\mathrm{Cu}^{2+}$, respectively (Figure $\left.\mathrm{S} 13\right) .[39,40]$ 


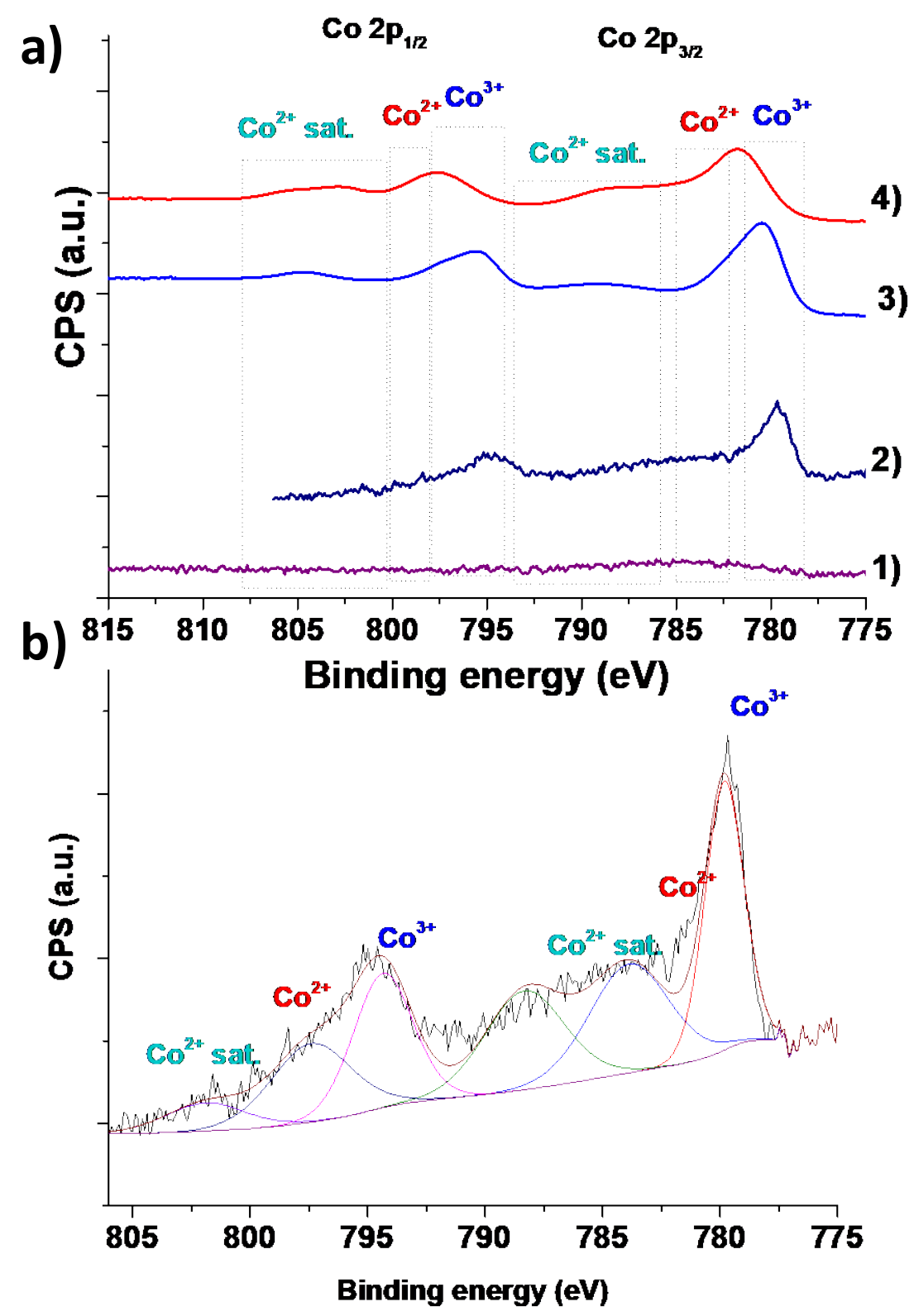

Figure 5. XP spectra of $\mathrm{Co}(0.2 \mathrm{wt} \%) / \mathrm{ACN}$ (a1) and $\mathrm{Co}_{\text {ox }}(0.2 \mathrm{wt} \%) / \mathrm{ACN}$ (a2). Deconvoluted XP spectrum of $\mathrm{Co}_{\mathrm{ox}}(0.2 \mathrm{wt} \%) / \mathrm{ACN}$.

Diffuse reflectance UV-Vis spectra of several of the cobalt oxide catalysts under study are presented in Figure S14. Commercial $\mathrm{Co}_{3} \mathrm{O}_{4}$ and as-prepared $\mathrm{Co}_{o x}$ solids exhibit visible absorption bands in the regions about 400 and $650 \mathrm{~nm}$ that should correspond to the $\mathrm{O}^{2-}-\mathrm{Co}^{2+}$ and $\mathrm{O}^{2-}-\mathrm{Co}^{3+}$ ligand to metal charge transfer, respectively. In the cobalt oxide NPs supported on ACN, these absorption bands seem to be masked by the black ACN support.[41] 


\subsection{Catalytic activity}

The series of prepared catalysts was tested for phenol degradation using PMS as oxidant. Phenol was selected as organic pollutant because is a non-biodegradable, recalcitrant and toxic organic compound for the aquatic environment. Preliminary tests indicate that phenol adsorption on the three different ACs is lower than $5 \%$ (data not shown). Blank control experiments reveal that activation of PMS in the absence of catalyst is negligible (Figure S15). Interestingly, ACN can somehow activate PMS under the present reaction conditions (Figure S15). This fact is not unexpected considering recent publications that have reported the use carbon-based materials to activate PMS.[10] As expected, deposition of cobalt NPs supported on the carbonaceous materials increases the catalytic activity for PMS activation and phenol decomposition (Figures 6 and Table 2). Figure 6b shows that oxidized cobalt NPs supported on ACs (Coox supported on AC, ACT or ACN) are more active than analogous non-oxidized ones, even though the cobalt particle size distribution of the former indicates the larger average dimensions of Co particles after oxidation. It is a general observation in the field of catalysis by metal NPs that the catalytic activity increases as the size of the metal NP decreases.[42] In the present case, however, it seems that the oxidation state of cobalt NPs is more important than the particle size distribution for the activation of PMS. These results agree with previous reports showing the higher activity of cobalt oxides respect to metallic cobalt. 10,11 

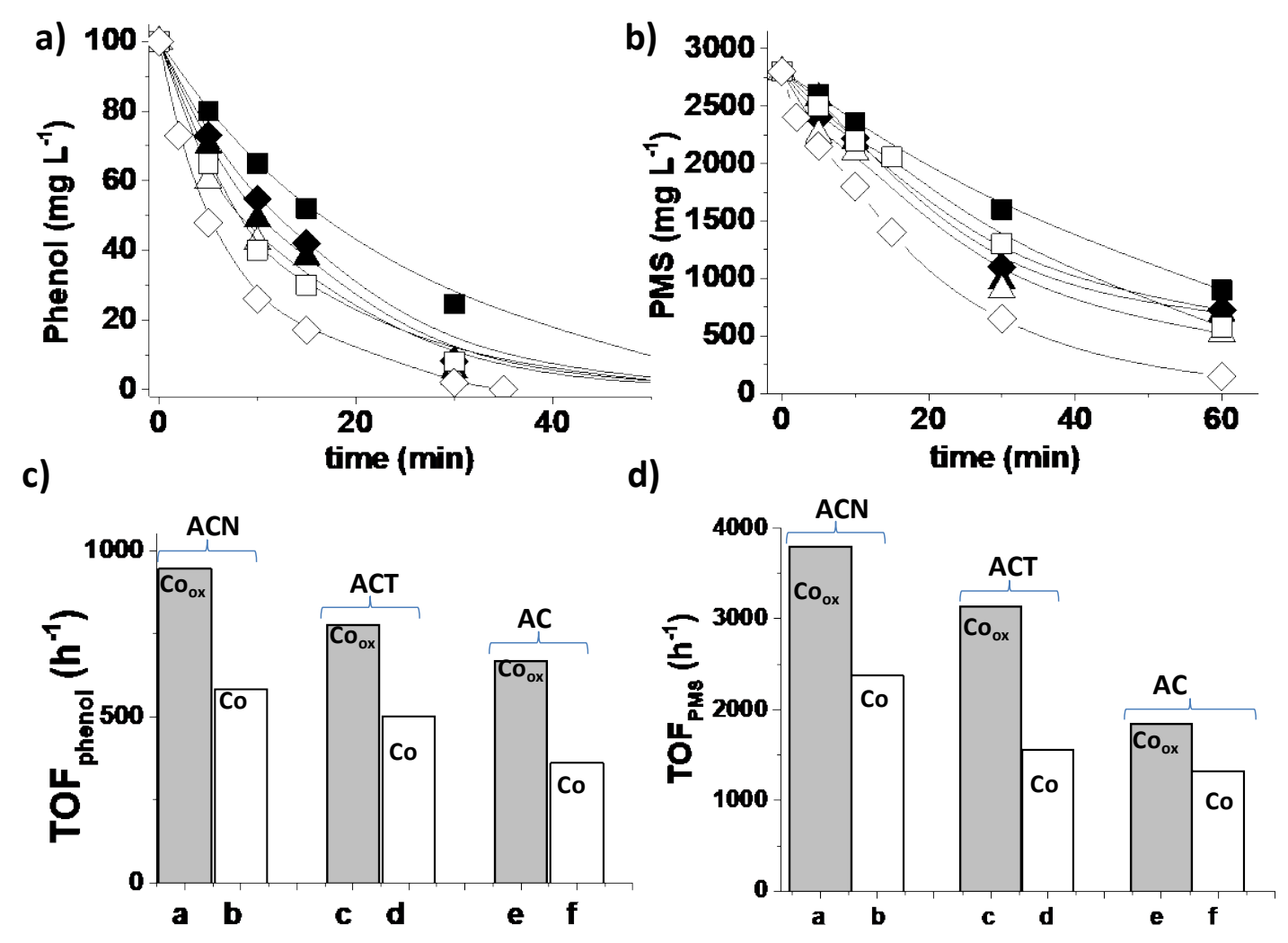

Figure 6. Phenol degradation (a), PMS decomposition (b) and corresponding TOF (c, d) using Co-NPs supported on $\mathrm{AC}(\boldsymbol{\bullet}, \mathrm{f}), \operatorname{ACT}(\boldsymbol{\Delta}, \mathrm{d})$ and $\mathrm{ACN}(\diamond, \mathrm{b})$ and $\mathrm{Co}_{3} \mathrm{O}_{4}-\mathrm{NPs}$ supported on $\operatorname{AC}(\square, \mathrm{e}), \operatorname{ACT}(\Delta, \mathrm{c})$ and $\operatorname{ACN}(\diamond$, a). Reaction conditions: Catalyst (200 $\mathrm{mg} \mathrm{L}^{-1} ; 0.0067 \mathrm{mM}$ of supported cobalt), phenol (100 mg/L; $\left.1.06 \mathrm{mM}\right)$, PMS (2800 mg $\left.\mathrm{L}^{-1} ; 9.1 \mathrm{mM}\right), 20^{\circ} \mathrm{C}, \mathrm{pH} 7$.

Among the different catalysts based on $\mathrm{Co}_{\mathrm{ox}}$ NPs supported on ACs (AC, ACN and ACT), the highest catalytic activity has been achieved using the Coox $(0.2 \mathrm{wt} \%) / \mathrm{ACN}$ material that corresponds to that with the smallest cobalt oxidized metal NPs (Figure 6). Based on the catalytic results and the characterization data of the ACs, it is proposed that the higher amount of oxygen functional groups in the ACN support generated by the chemical treatment allows a good dispersion of small cobalt NPs with enhanced catalytic activity respect to analogous ACT or AC supports. 
Figure 7 shows that the catalytic activity of $\mathrm{Co}_{\text {ox }}$ supported on ACN increases as the cobalt loading decreases from 1.0 to $0.2 \mathrm{wt} \%$. This fact was attributed to the lower cobalt particle size distribution observed with the sample at lower cobalt loading. Figure 7 also presents the influence of the metal nature on the resulting catalytic activity for phenol degradation and PMS decomposition. The catalyst based on Co ox NPs supported on ACN exhibiting higher activity than analogous catalysts based on $\mathrm{Fe}_{\text {ox }}$ or $\mathrm{Cu}_{\text {ox }}$ NPs supported on ACN at the same metal loading (1 wt\%).

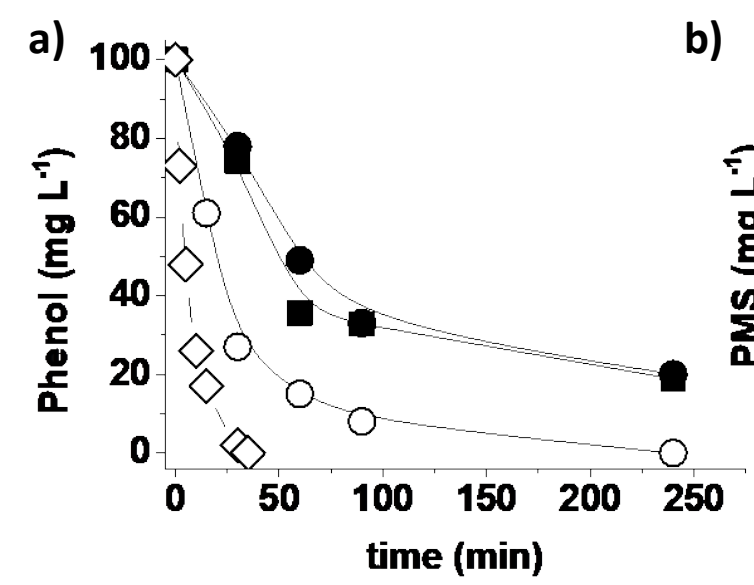

b) 3000

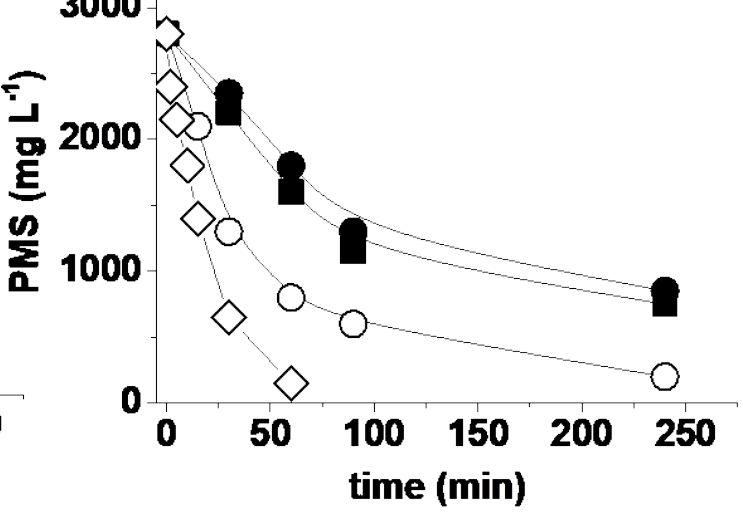

Fig 7: Phenol degradation (a) and PMS decomposition (b) using Coox-NPs supported on ACN at $0.2(\diamond)$ and 1 wt\% cobalt loading $(\circ)$. Fe ox $_{\text {-NPs }}(\boldsymbol{\bullet})$ and $\mathrm{Cu}_{\mathrm{ox}}-\mathrm{NPs}(\bullet)$ supported on ACN at $1 \mathrm{wt} \%$ metal loading. Reaction conditions: Catalyst (0.0067 mM of supported metal), phenol (100 mg/L; $1.06 \mathrm{mM})$, PMS (2800 mg L-1; $9.1 \mathrm{mM}), 20^{\circ} \mathrm{C}, \mathrm{pH} 7$.

In order to put into context the catalytic activity of $\mathrm{Co}_{\text {ox }}(0.2 \mathrm{wt} \%) \mathrm{ACN}$ its catalytic activity was compared to that obtained when using homogeneous $\mathrm{Co}^{2+}$ ions, unsupported as-made $\mathrm{Co}_{o x} \mathrm{NPs}$ or commercial $\mathrm{Co}_{3} \mathrm{O}_{4}$ solid as catalysts. Frequently, phenol oxidation in water by PMS is faster when using $\mathrm{Co}^{2+}$ ions as homogeneous catalyst respect to the use of heterogeneous cobalt catalysts, such as cobalt oxide doped carbon aerogel. ${ }^{[21]}$ Surprisingly, in the present work the activity of $\mathrm{Co}_{\text {ox }}(0.2 \mathrm{wt} \%) \mathrm{ACN}$ is higher (TOFPMS 3800, TOF $F_{\text {phenol }} 950$ ) than that obtained using $\mathrm{Co}^{2+}$ ions (TOFpMs 1460 , TOF phenol $_{330}$ ) or 
as-prepared unsupported Coox NPs (TOFpms 740, TOF phenol 190). These observations highlight the importance of high surface area, AC surface functionalization with the appropriate nature and population of oxygen functional groups for the dispersion of small metal NPs with specific metal oxidation state.
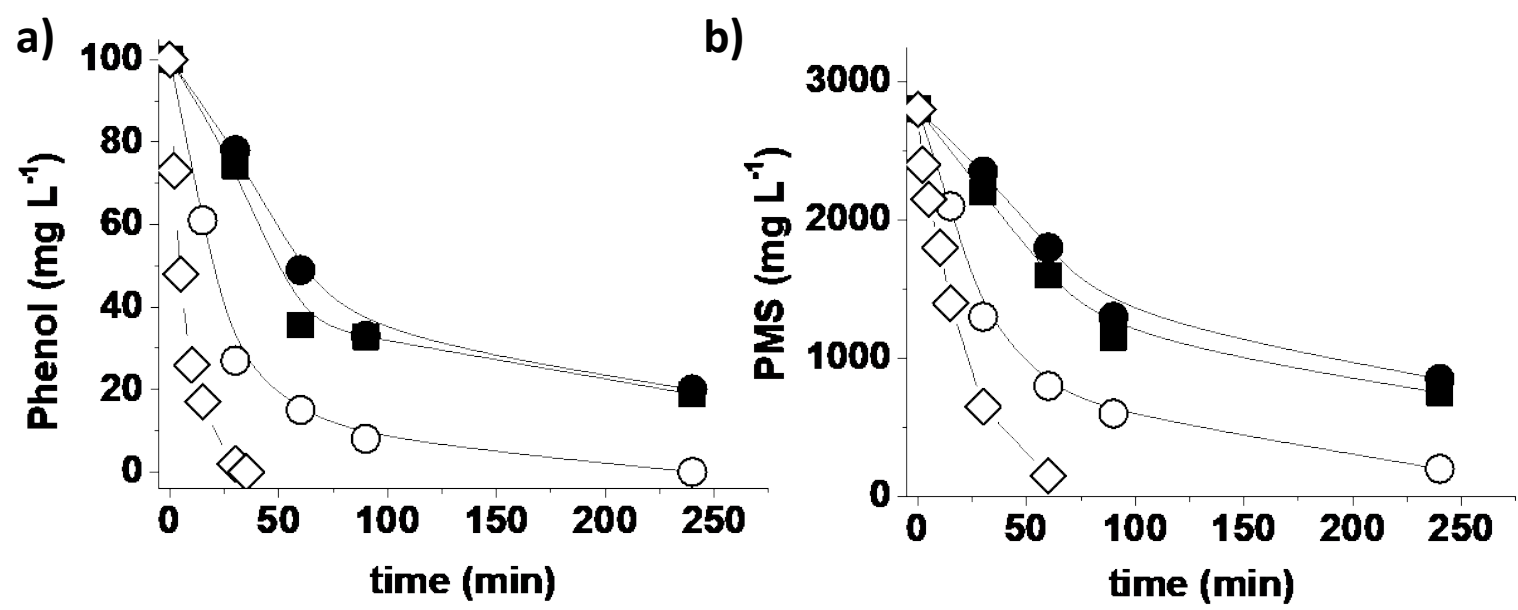

Fig 8: Phenol degradation (a) and PMS decomposition (b) using Coox -NPs supported on ACN at 0.2 wt\% metal loading $(\diamond)$, using commercial $\mathrm{Co}_{3} \mathrm{O}_{4} \mathrm{NPs}(\odot)$, as-prepared unsupported $\mathrm{Co}_{\mathrm{ox}} \mathrm{NPs}(\bullet)$ and using $\mathrm{Co}^{2+}$ as homogeneous catalyst (๘). Reaction conditions: Catalyst (0.0067 mM of cobalt), phenol (100 mg/L; $1.06 \mathrm{mM})$, PMS (2800 mg L $\left.{ }^{-1} ; 9.1 \mathrm{mM}\right), 20{ }^{\circ} \mathrm{C}, \mathrm{pH} 7$.

One of the main problems associated with AOPs for water treatment is the strong dependence of their efficiency with the $\mathrm{pH} .[13,24]$ The use PMS has been reported as one promising alternative to the use of other oxidants such as $\mathrm{H}_{2} \mathrm{O}_{2}$ that typically requires strongly acidic $\mathrm{pH}$ solutions to achieve good efficiencies. ${ }^{10,11}$ Herein it has been shown that $\mathrm{Co}_{\mathrm{ox}} / \mathrm{ACN}$ is an optimal catalyst for PMS activation and phenol degradation even at neutral $\mathrm{pH}$ values (Figure 9). This constitutes a significant advantage compared to other heterogeneous Fenton processes that only operate efficiently at strongly acidic pH values.[3, 5, 13] Previous studies using homogenous $\mathrm{Co}^{2+}$ ions or heterogeneous cobalt NPs supported on carbonaceous materials[43] have also found that those catalysts exhibit 
optimal performance at neutral or quasi-neutral $\mathrm{pH}$ values.[10, 44] As it can be seen in Figure 9 the catalytic activity of $\mathrm{Co}_{\mathrm{ox}}(0.2 \mathrm{wt} \%) / \mathrm{ACN}$ for PMS activation and phenol degradation increases with the $\mathrm{pH}$. On one hand, an increase of the $\mathrm{pH}$ favors the formation of the more easily oxidizable phenolate. On the other hand, PMS decomposition should be a function of its speciation in the reaction medium.[45] Acidic $\mathrm{pH}$ values would increase the PMS stability and, therefore, it could make more difficult its activation towards radical formation.[43, 46] Considering that PMS has a $\mathrm{pK}_{2}$ in water about 9.4, the prevalent species at quasi-neutral $\mathrm{pH}$ values should be $\mathrm{HSO}_{5}^{-}$(Figure 9, equation 6) and, therefore, it seems that the selective formation of $\mathrm{SO}_{4}{ }^{-}$and/or $\mathrm{HO}$ radicals is favored (Eqs. 1, 3 and 4).[45] In contrast, at pH values above 10, PMS coexists in the form of both $\mathrm{HSO}_{5}{ }^{-}$and $\mathrm{SO}_{5}{ }^{2-}$ according equations 7 and 8.[45] Equation 7 represents a nucleophilic attack on the peroxide hydrogen of $\mathrm{HSO}_{5}{ }^{-}$by $\mathrm{SO}_{5}{ }^{2-}$ that would form a transition state $\left(\mathrm{HSO}_{5} \cdot \mathrm{SO}_{5} \cdot \mathrm{H}_{2} \mathrm{O}\right)^{3-}$ that leads to the formation of $\mathrm{HSO}_{6}{ }^{-}$(Equation 7). Finally, according Equation $8 \mathrm{HSO}_{6}{ }^{-}$in the presence of hydroxyl ions decomposes to form $\mathrm{O}_{2}$ through a non-radical reaction pathway. The influence of $\mathrm{pH}$ on the activity of the $\mathrm{Co}_{\text {ox }}(0.2 \mathrm{wt} \%) / \mathrm{ACN}$ catalyst agrees with the reported prior literature data reflected by Equations 1-8.

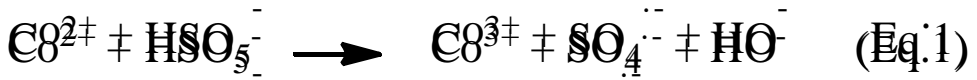

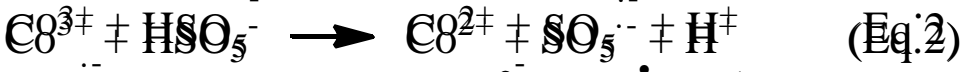

$$
\begin{aligned}
& \mathrm{SO}_{4 .-}^{--} \neq \mathrm{H}_{2} \mathrm{O} \rightarrow \mathrm{SO}_{4}^{2-} \neq \mathrm{OH}^{2} \neq \mathrm{H}^{\ddagger} \quad \text { (E母. } 3 \text { ) }
\end{aligned}
$$

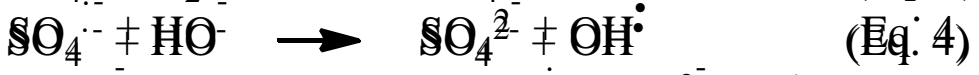

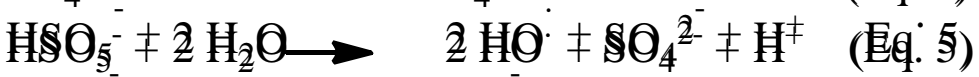

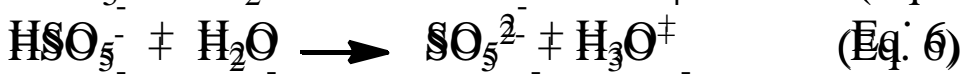

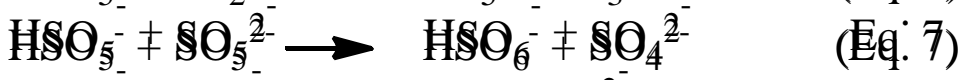

$$
\begin{aligned}
& \mathrm{HSO}_{6}^{-} \neq \mathrm{HO}^{-} \rightarrow \mathrm{H}_{2} \mathrm{O} \neq \mathrm{SO}_{4}{ }^{2^{-}} \neq \mathrm{O}_{\mathrm{z}} \quad \text { (Eq. }
\end{aligned}
$$



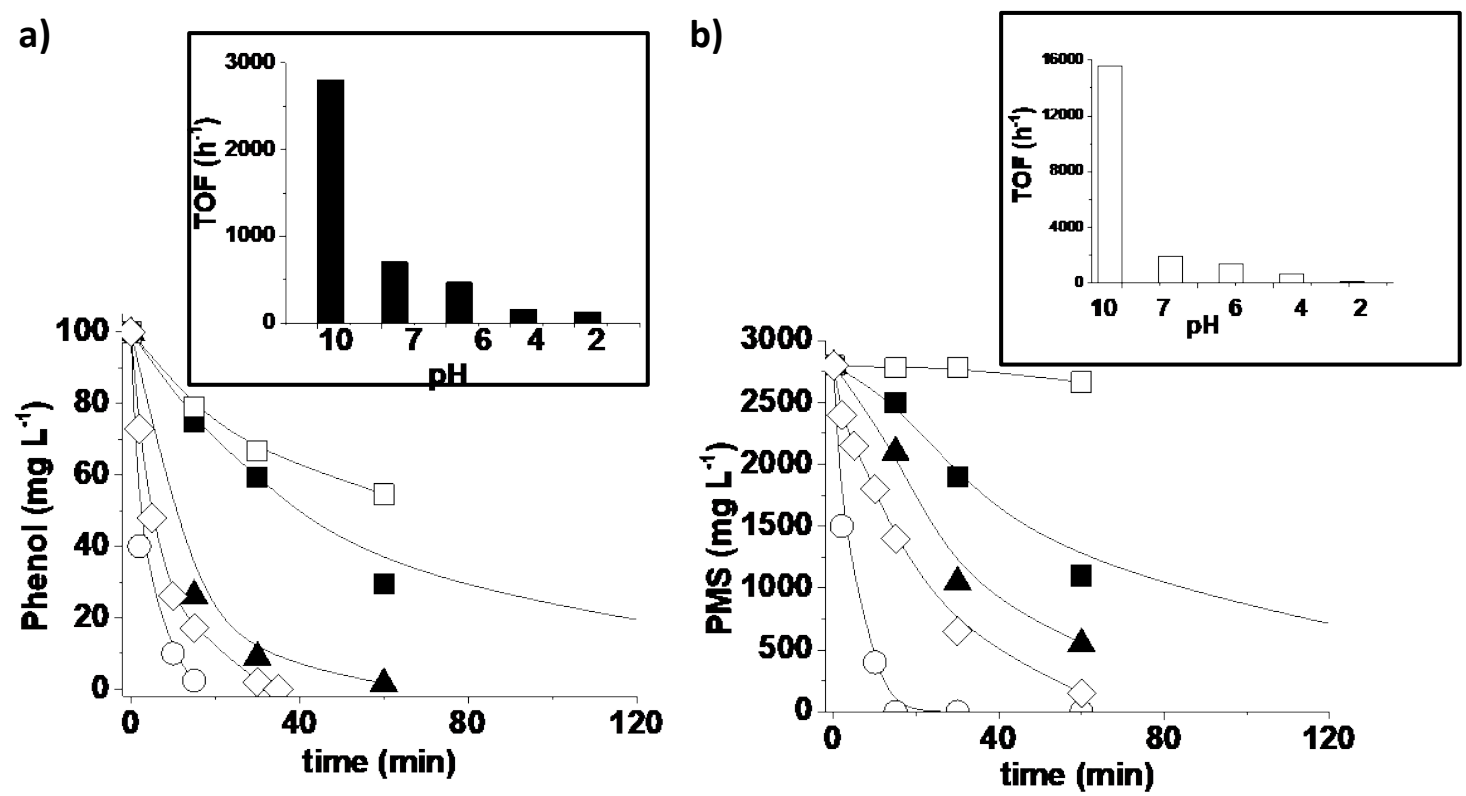

Figure 9. Phenol degradation (a), PMS decomposition (b) and respective TOF values for phenol (black bar) and PMS (white bar) using $\mathrm{Co}_{\mathrm{ox}} / \mathrm{ACN}$ at pH 2 (口), pH4 (घ), pH 6 ( $\mathbf{\Delta}$ ), pH $7(\diamond)$ and $\mathrm{pH} 10(\circ)$. Reaction conditions: Catalyst (200 mg L $\mathrm{L}^{-1} ; 0.0067 \mathrm{mM}$ of supported cobalt), phenol (100 mg/L; $1.06 \mathrm{mM})$, PMS (2800 mg L $\left.{ }^{-1} ; 9.1 \mathrm{mM}\right), 60{ }^{\circ} \mathrm{C}, \mathrm{pH}$ as indicated.

Other important parameter that should be considered when developing alternative AOPs is the amount of oxidant employed respect to the substrate.[13, 14, 42] Figure 10 shows the influence of the initial PMS concentration on the catalytic activity for phenol degradation. An optimal PMS to phenol molar ratio of 9.3 was found for phenol degradation and, more importantly, degradation of its even more toxic reaction intermediates namely catechol, hydroquinone and p-benzoquinone (Figure S16). This value is lower than that required in other systems for complete degradation of phenol such as cobalt oxide supported on AC (oxone to phenol molar ratio 25),[20] cobalt oxide doped on carbon aerogel[21] or carbon xerogel[47] with an oxone to phenol molar ratio 12.8 even though still some toxic intermediates such as hydroquinone and $p$-benzoquinone were detected.[21] Thus, $\mathrm{Co}_{3} \mathrm{O}_{4}$ NPs supported in reduced graphene oxide employs a 
phenol to PMS molar ratio of about 60 or $\mathrm{MnO}_{2} / \mathrm{ZnFe}_{2} \mathrm{O}_{4}$ uses a phenol to PMS ratio of 31.[48] In the present work, under optimized reaction conditions a notable TOC reduction of about $70 \%$ was measured. Furthermore, a good relationship was also observed between the TOF for phenol degradation and the amount of PMS (Figure 10d). The TOF values increase along the PMS concentration with the maximum values of 3300 and 550 $\mathrm{h}^{-1}$ achieved for PMS decomposition and phenol degradation, respectively.

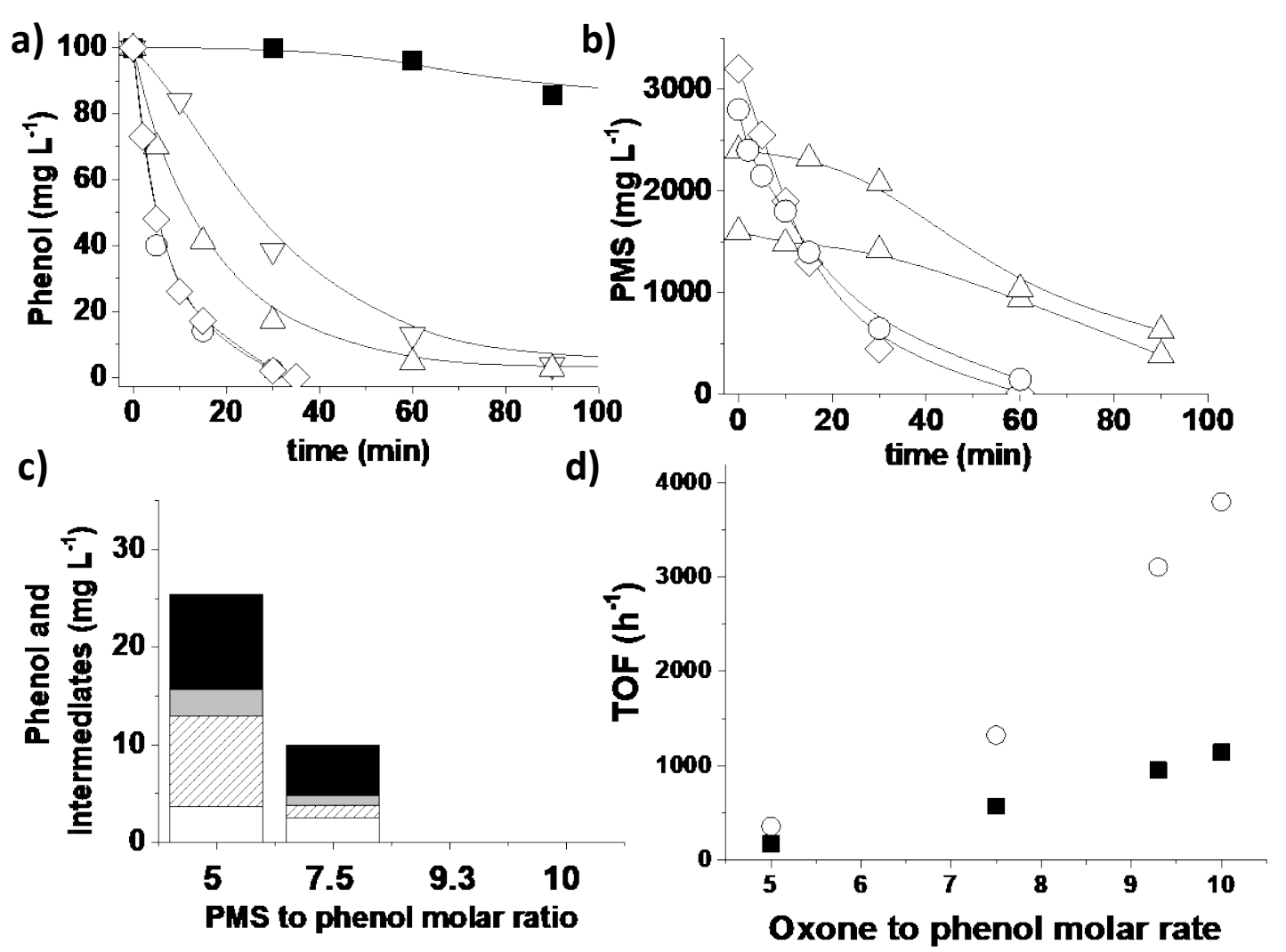

Figure 10: Phenol degradation (a), PMS decomposition (b), remaining phenol and intermediates (c) and TOF for phenol degradation (०) and PMS decomposition ( $\square$ ) measured at 15 min (d) using Coox/ACN with different PMS dosages: $1600 \mathrm{mg} \mathrm{L}^{-1}$ (10.5 mM, 匹), $2400 \mathrm{mg} \mathrm{L}^{-1}$ (7.9 mM, o), $2800 \mathrm{mg} \mathrm{L}^{-1}$ (9.1 mM, А ), $3200 \mathrm{mg} \mathrm{L}^{-1}$ (10.5 mM, 口) and $4000 \mathrm{mg} \mathrm{L}^{-1}$ (13.5 mM, •). Reaction Conditions: Catalyst (200 mg L $\mathrm{m}^{-1}$; 0.0067 mM of supported cobalt), phenol (100 mg L $\left.{ }^{-1}\right)$, PMS (as indicated), $20^{\circ} \mathrm{C}$, initial pH 7. 
The catalytic activity of the most active catalyst prepared in this work $\mathrm{Co}_{\text {ox }}(0.2$ wt\%)/ACN using PMS as oxidant was compared with that of $\mathrm{H}_{2} \mathrm{O}_{2}$ at $\mathrm{pH} 4$ and 7 (Figure S17). The degradation of phenol by $\mathrm{H}_{2} \mathrm{O}_{2}$ and $\mathrm{Coox}(0.2 \mathrm{wt} \%) / \mathrm{ACN}$ as catalyst does not take place at neither $\mathrm{pH}$ value of 4 or 7 . This observation agrees with previous reports showing the higher activity of the homogeneous $\mathrm{Co}^{2+} / \mathrm{PMS}$ systems respect to $\mathrm{Co}^{2+} / \mathrm{H}_{2} \mathrm{O}_{2} \cdot[49,50]$

The influence of the temperature on the catalytic activity for PMS activation and phenol degradation using Coox/ACN as catalyst allowed an estimation of the apparent activation energy for these processes at $\mathrm{pH} 7$ (Figure 11). The estimated Ea for PMS decomposition and phenol degradation is about 30 and $32 \mathrm{~kJ} \mathrm{~mol}^{-1}$, respectively. These Ea values indicate that the catalytic ROS generated during the PMS decomposition, such as $\mathrm{SO}_{4}{ }^{-}$and $\mathrm{HO}^{\circ}$ (see reaction mechanism below), react in an almost barrierless process for phenol degradation. Furthermore, the lower Ea values at $\mathrm{pH} 7$ compared to $\mathrm{pH} 4$ reinforces the idea that is possible to develop AOP based on cobalt-catalyzed PMS activation for aqueous pollutant degradation at neutral $\mathrm{pH}$ values. These low Ea values obtained with $\operatorname{Co}_{\text {ox }}(0.2 \mathrm{wt} \%) / \mathrm{ACN}$ compare favorably with similar systems based on cobalt oxide doped carbon aerogel (Ea for phenol $62.9 \mathrm{~kJ} \mathrm{~mol}^{-1}$, $\mathrm{pH}$ not indicated),[21] cobalt oxide loaded on carbon xerogel (Ea for phenol degradation $48.3 \mathrm{~kJ} \mathrm{~mol}^{-1}$, pH not indicated), [47] cobalt oxide on activated carbon (Ea for phenol degradation $59.7 \mathrm{~kJ} \mathrm{~mol}^{-}$ 1, pH not indicated),[20] and other cobalt catalysts on other supports on such as ZSM5, mesoporous silicas such as SBA-15[51] or $\mathrm{SiO}_{2}{ }^{37}$ with values ranging between 61.7 and $75.5 \mathrm{~kJ} \mathrm{~mol}^{-1}$. While the previous commented literature Ea values refer to phenol degradation analogous Ea data referring to PMS decomposition are not available. It should be, however, commented the Ea for PMS decomposition is also an important 
kinetic parameter when comparing two activities of different catalysts, since it refers to the generation of the primary reactive oxygen radicals.

a)

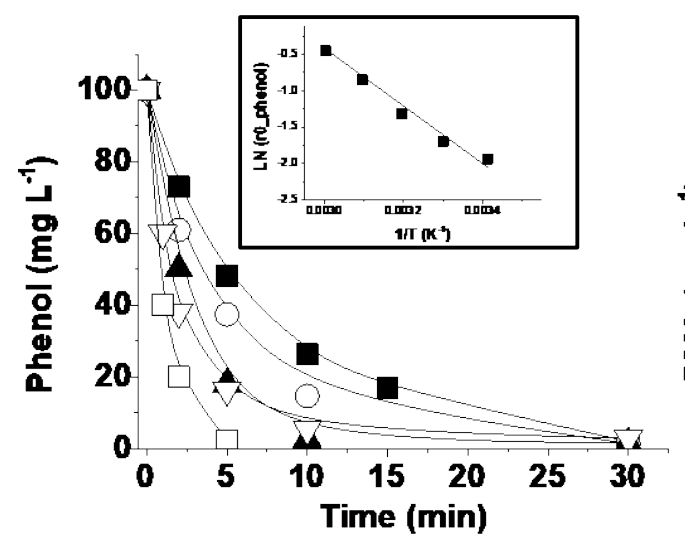

b)

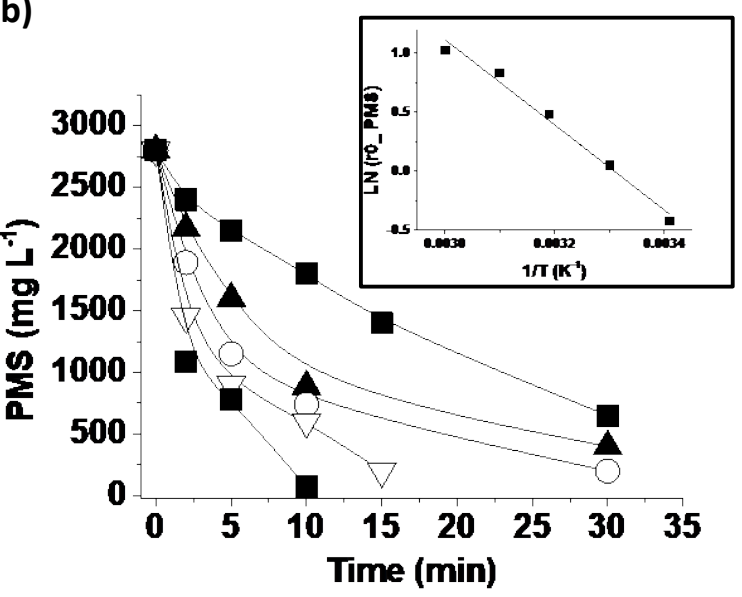

Figure 11. Phenol degradation (a) and PMS decomposition (b) using Coox/ACN at $20^{\circ} \mathrm{C}$ $(\boldsymbol{\square}), 30{ }^{\circ} \mathrm{C}(\circ), 40{ }^{\circ} \mathrm{C}(\boldsymbol{\Delta})$ and $50{ }^{\circ} \mathrm{C}(\nabla)$. The inset shows the estimation of the apparent Ea of the process. Reaction conditions: Catalyst (200 mg L ${ }^{-1} ; 0.0067 \mathrm{mM}$ of supported cobalt), phenol (100 mg/L; $1.06 \mathrm{mM}$ ), PMS (2800 mg L-1; $9.1 \mathrm{mM}$ ), temperature as indicated, initial pH 7.

The stability of the Coox/ACN catalyst was assessed by performing eight consecutive uses of the same sample at $\mathrm{pH} 7$ without observing decrease of the catalytic activity. Cobalt leaching from the solid catalyst to the solution after running the reaction at $\mathrm{pH} 7$ was below detection limit $(<1.0 \mu \mathrm{g} / \mathrm{L})$. The absence of cobalt leaching from $\operatorname{Coox}(0.2 \mathrm{wt} \%) / \mathrm{ACN}$ catalyst compares favorably with the cobalt leaching measured for PMS activation when using $\mathrm{SiO}_{2}, \mathrm{TiO}_{2}$ or $\mathrm{Al}_{2} \mathrm{O}_{3}$ as support with values of cobalt leaching of $0.75,2.83$ or $0.94 \mathrm{mg} \mathrm{L}^{-1}$, respectively (pH not indicated).[41] Other systems based on cobalt oxide on carbon aerogel resulted in cobalt leaching around $1 \mathrm{mg} \mathrm{L}^{-1}$ ( $\mathrm{pH}$ of reaction not indicated) and concomitant decrease of catalytic activity for phenol degradation upon reuse.[21] In other study, Co NPs embedded on carbon nanofibers resulted in a quite stable catalyst for PMS activation, although still a cobalt leaching of $20 \mu \mathrm{g} \mathrm{L}^{-1}$ was 
measured. [43] Another study that employed cobalt supported on $\mathrm{TiO}_{2}$ as photocatalyst under UV irradiation have resulted in cobalt leaching values of $25 \mu \mathrm{g} \mathrm{L}^{-1}$. [18] In our case, blank control experiments using this trace amount of cobalt to promote phenol degradation by $\mathrm{PMS}$ at $\mathrm{pH} 7$ or 4 resulted in negligible catalytic activity indicating the heterogeneity of the reaction process. Importantly, TEM images of eight-times used

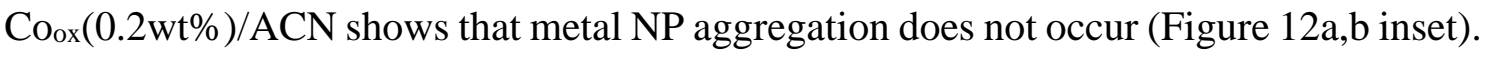

Furthermore, productivity experiments using a high concentration of phenol (10 $\mathrm{g} \mathrm{L}^{-1} ; 106.4 \mathrm{mM}$ ) and PMS (280 $\mathrm{g} \mathrm{L}^{-1} ; 912 \mathrm{mM}$ ) respect to the catalyst (200 $\mathrm{mg} \mathrm{L}^{-1}$; $0.0067 \mathrm{mM}$ of supported cobalt) allow determining an accumulated TON after three cycles for phenol and PMS decomposition as high as 39,000 and 400,000, respectively. Similarly, TOF values for the first catalytic cycle about 68,000 and $8 \cdot 10^{5} \mathrm{~h}^{-1}$ for phenol degradation and PMS were estimated at 5 min of reaction. These TON and TOF values are much higher compared to those reported in the literature using heterogeneous metal catalysts for water pollutant degradation using PMS as oxidant that frequently are lower than 100.[9, 20, 21, 41, 43, 47, 48, 52-54] As commented, different heterogeneous catalysts have been reported for PMS activation but, however, most of these papers do not measure PMS decomposition and, therefore, estimation of TOF and TON values for PMS decomposition is not possible in those cases.

In this study, the good stability of the Coox/ACN catalyst may be attributed to the presence of oxygen functional groups able to establish strong anchoring interaction with the cobalt NPs. The reusability data of $\mathrm{Co}_{\text {ox }} / \mathrm{ACN}$ compares favorably with analogous catalyst based on oxidized cobalt NPs supported on carbon microspheres,[54] on $\mathrm{SiO}_{2}[17$, 41] or on $\mathrm{TiO}_{2}$ [41] and $\mathrm{Al}_{2} \mathrm{O}_{3}$,[41] among others,[55] that suffer deactivation upon reuse. 

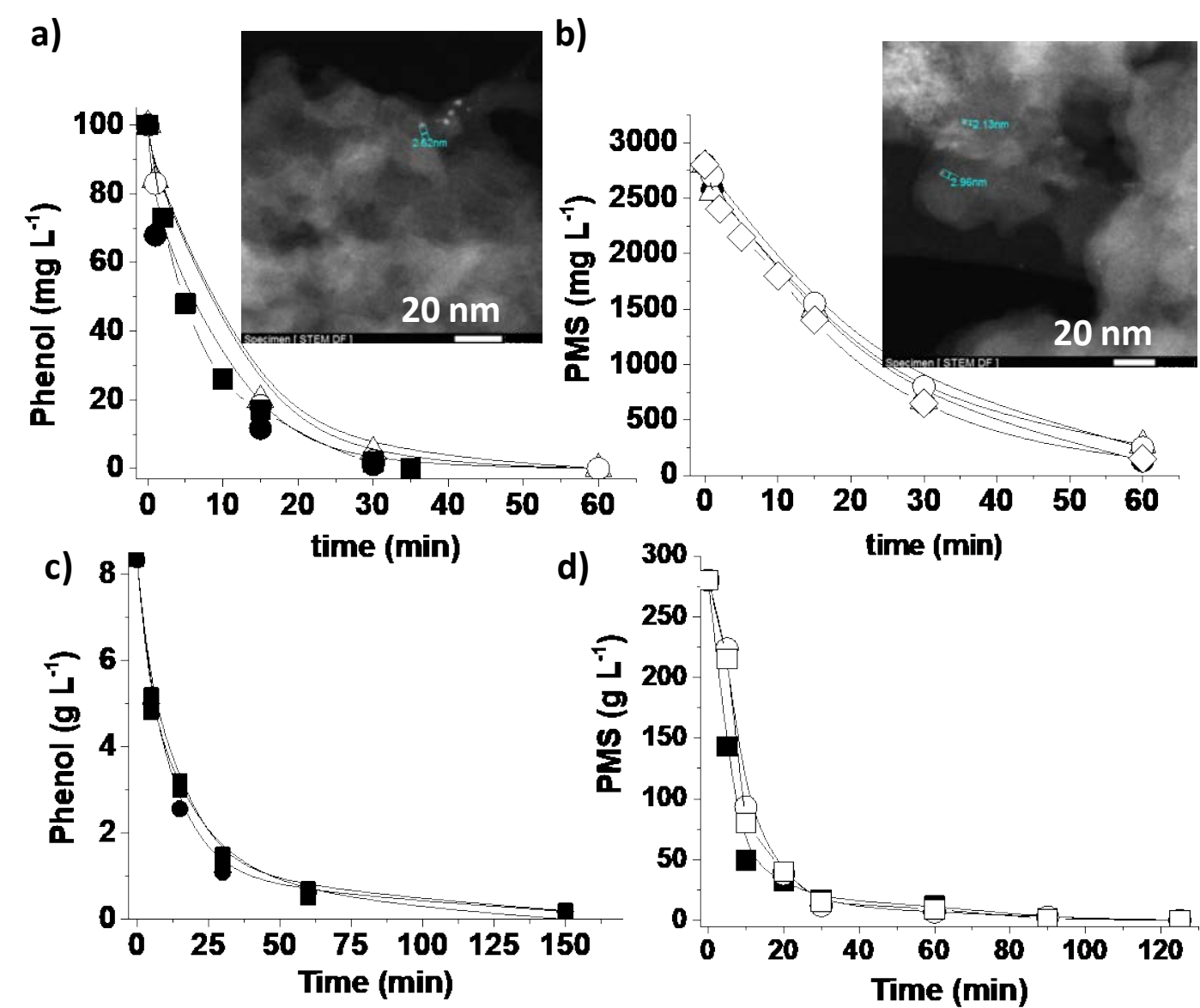

Figure 12. Reusability of Coox/ACN at pH 7 and $20^{\circ} \mathrm{C}$ under regular (a, b) or under productivity test (c, d) conditions for phenol degradation (a, c) and PMS decomposition

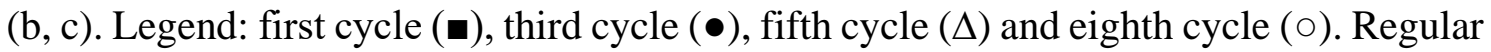
reaction conditions: Catalyst (200 $\mathrm{mg} \mathrm{L}^{-1} ; 0.0067 \mathrm{mM}$ of supported cobalt), phenol (100 mg L ${ }^{-1} ; 1.06 \mathrm{mM}$ ), PMS (2800 $\left.\mathrm{mg} \mathrm{L}^{-1}, 9.1 \mathrm{mM}\right), 20{ }^{\circ} \mathrm{C}$, $\mathrm{pH}$ 7. Productivity reaction conditions: Catalyst (200 mg L ${ }^{-1}$; $0.0067 \mathrm{mM}$ of supported cobalt), phenol (10 g/L; 106.4 mM), PMS (280 g L $\left.{ }^{-1}, 912 \mathrm{mM}\right), 20^{\circ} \mathrm{C}$, initial $\mathrm{pH} 7$.

\subsection{Reaction mechanism}

In order to determine the reactive oxygen species generated in the catalytic system for PMS activation by the action of Coox/ACN as catalyst, a series of selective radical quenching experiments and EPR measurements were performed. As preliminary 
experiments the influence of ambient oxygen in the catalytic reaction was evaluated. Figure 13 shows that the presence of oxygen only slightly accelerates both phenol degradation and PMS decomposition, therefore, suggesting that oxygen participates in the radical reaction mechanism. The possible formation of radical species was further evaluated using DMSO as selective hydroxyl radical scavenger. The inhibition of the reaction by presence of DMSO indicates that hydroxyl radicals should be the main species responsible of the observed phenol degradation.[56] EPR measurements using PBN as spin trap clearly shows the formation of the $\mathrm{PBN}-\mathrm{OH}$ adduct under conditions relevant to phenol degradation. Note that the control in the absence of Coox/ACN only allows to detect very weak EPR signals, indicating that ${ }^{\circ} \mathrm{OH}$ radicals are formed mainly due to the activity of the Coox/ACN catalyst (Figure 14c-d).
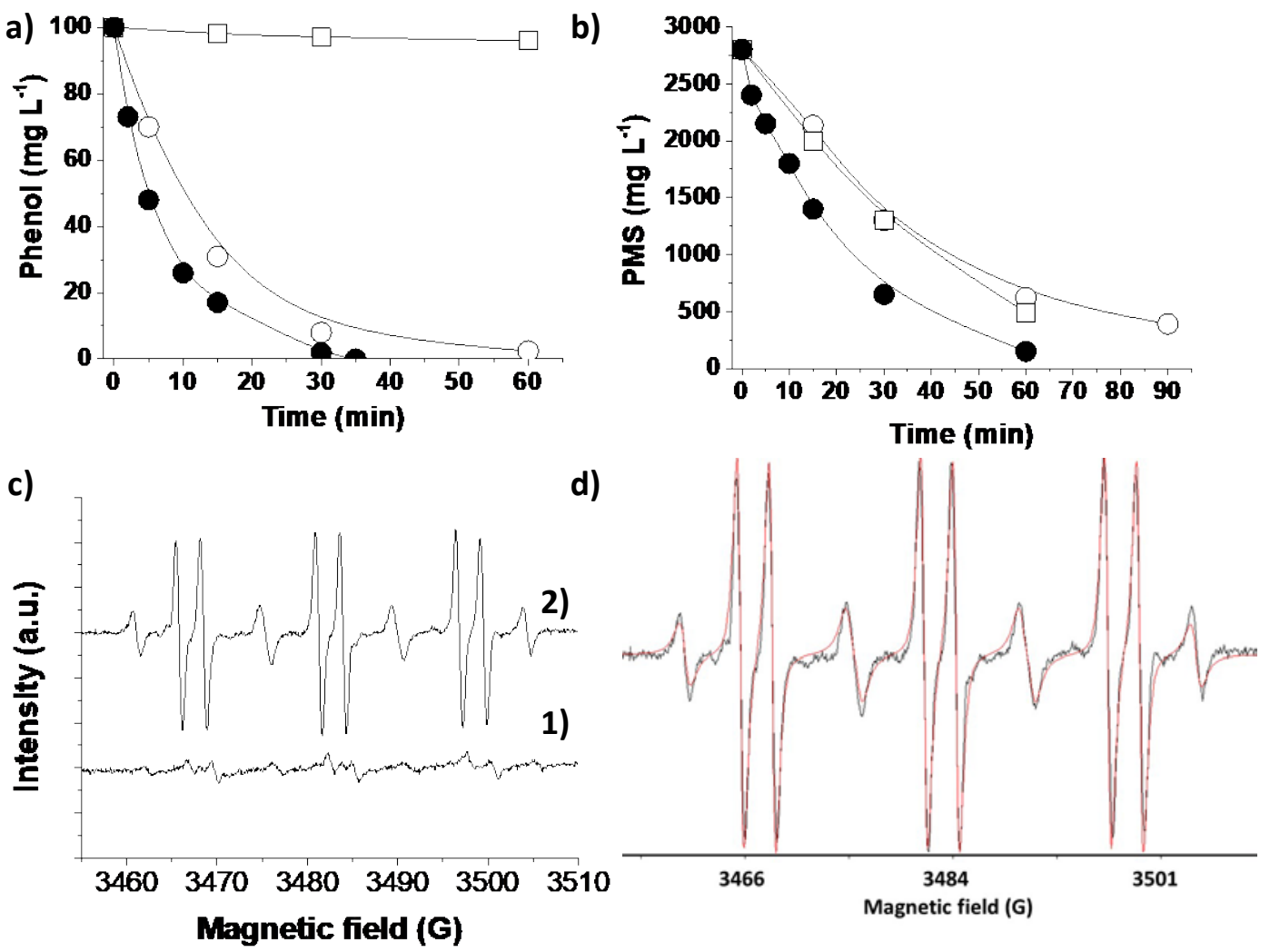

Figure 13. (a) Phenol degradation and (b) PMS decomposition using Coox/ACN as catalyst. Legend: air atmosphere $(\bullet)$, air atmosphere with the presence of DMSO ( $\square)$, 
nitrogen atmosphere (०). Reaction conditions: Catalyst (200 $\mathrm{mg} \mathrm{L}^{-1} ; 0.0067 \mathrm{mM}$ of supported cobalt), phenol (100 mg/L; $1.06 \mathrm{mM})$, PMS (2800 mg L $\left.\mathrm{m}^{-1}, 9.1 \mathrm{mM}\right), 20{ }^{\circ} \mathrm{C}$, initial pH 7, DMSO to PMS molar ratio 10. (c) Experimental EPR spectra recorded in $\mathrm{H}_{2} \mathrm{O}$ at $\mathrm{pH} 7$ in the presence of PMS and the absence (1) or in the presence of Coox/ACN catalyst (2) after 15 min reaction time. (d) Experimental (black line) and simulated (red line) EPR spectra under (c) conditions. Hyperfine coupling constants of PBN-OH ( 85 $\%$ area) $\mathrm{AG}_{\mathrm{N}}=15.4$ and $\mathrm{AG}_{\mathrm{H}}=2.7$ and tert-butyl aminoxyl from degraded $\mathrm{PBN} \mathrm{AG}_{\mathrm{N}}=$ 15.58 and $\mathrm{AG}_{\mathrm{H}}=13.90$.

Based on these results a one-electron transfer process from PMS that reduces Co(III) to $\mathrm{Co}(\mathrm{II})$ is proposed. Then, catalytic cycle involves the oxidation of $\mathrm{Co}(\mathrm{II})$ to $\mathrm{Co}(\mathrm{III})$ and formation of $\mathrm{SO}_{4}{ }^{--}$radicals.[10, 11] $\mathrm{SO}_{4}{ }^{-}$radicals can instantaneously react with $\mathrm{H}_{2} \mathrm{O}$ leading to the formation of hydroxyl radicals. [10, 11]

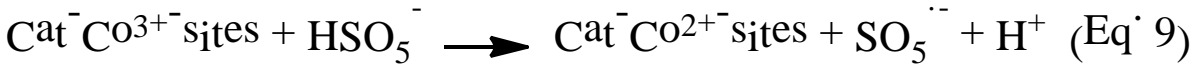

$$
\begin{aligned}
& \left.\mathrm{Cat}^{-} \mathrm{C}^{\mathrm{O}^{+-}} \mathrm{Sites}^{+} \mathrm{SO}_{5}{ }^{\cdot-}+\mathrm{H}^{+} \rightarrow \mathrm{Cat}^{-} \mathrm{CO}^{3^{+-}} \mathrm{Sites}^{+} \mathrm{SO}_{4}{ }^{\cdot-}+\mathrm{HO}^{-}{ }^{-} \mathrm{Eq}^{\cdot} 10\right) \\
& \mathrm{SO}_{4}^{-\cdot}+\mathrm{H}_{2} \mathrm{O} \rightarrow \mathrm{HSO}_{4}^{-}+\mathrm{HO} \quad\left(\mathrm{Eq}^{\cdot} 11\right)
\end{aligned}
$$

\subsection{Conclusions}

The present manuscript has shown the different catalytic behavior of a series of cobalt-containing ACs as a function of the surface pretreatment and metal oxidation state. It has been found that the catalyst activity for AOP using PMS at $\mathrm{pH} 7$ correlates well with the cobalt particle size, the smaller the dimension, the higher the catalyst activity. Furthermore, the oxidized supported cobalt NPs are catalytically more active than the reduced ones. In this regard, it has been established in the present study that by introducing oxygenated functional groups in AC by a chemical treatment using nitric acid 
(ACN), it is possible to obtain the cobalt oxide NPs with small average particle size $(4.7 \pm 0.05 \mathrm{~nm})$ and, therefore, exhibiting an enhanced catalytic activity towards PMS decomposition and phenol degradation. Furthermore, these surface oxygenated groups and the strong anchoring of oxidized cobalt NPs are also responsible for the stability of these NPs, minimizing their growth and allowing their reusability up to eight cycles without decay and the absence of cobalt leaching. It is remarkable that no cobalt leaching is detectable. Productivity tests using a large excess of phenol and PMS respect to the $\mathrm{Co}_{\text {ox }}(0.2 \mathrm{wt} \%) / \mathrm{ACN}$ catalyst allow to determine TON/TOF values as high as $39,000 / 68,000 \mathrm{~h}^{-1}$ for phenol and $400,000 / 8 \cdot 10^{5} \mathrm{~h}^{-1}$ for PMS, respectively. In this way the $\operatorname{Co}_{\text {ox }}(0.2 \mathrm{wt} \%) / \mathrm{ACN}$ catalyst compares favorably with those previously reported in the literature is herein described

\section{Acknowledgements}

Financial support by the Spanish Ministry of Economy and Competitiveness (Severo Ochoa, CTQ2015-65963-CQ-R1) and CTQ2014-53292-R is gratefully acknowledged. Generalidad Valenciana is also thanked for funding (Prometeo 2017/083). S.N. thanks financial support by the Fundación Ramón Areces (XVIII Concurso Nacional para la Adjudicación de Ayudas a la Investigación en Ciencias de la Vida y de la Materia, 2016).

\section{References}


[1] K. Ayoub, E.D. van Hullebusch, M. Cassir, A. Bermond, Application of advanced oxidation processes for TNT removal: A review, J. Hazard. Mater. 178 (2010) 10-28.

[2] M. Cheng, G. Zeng, D. Huang, C. Lai, P. Xu, C. Zhang, Y. Liu, Hydroxyl radicals based advanced oxidation processes (AOPs) for remediation of soils contaminated with organic compounds: A review, Chem. Eng. J. 298 (2016) 582-598.

[3] E. Neyens, Baeyens, J., A review of classic Fenton's peroxidation as an advanced oxidation technique, J. Hazard. Mater. 98 (2003) 33-50.

[4] M. Pera-Titus, V. García-Molina, M.A. Baños, J. Giménez, S. Esplugas, Degradation of chlorophenols by means of advanced oxidation processes: a general review, Appl. Catal. B-Environ. 47 (2004) 219-256.

[5] J.J. Pignatello, E. Oliveros, A. MacKay, Advanced oxidation processes for organic contaminant destruction based on the fenton reaction and related chemistry, Crit. Rev. Env. Sci. Tec., 36 (2006) 1-84.

[6] K. Demeestere, J. Dewulf, H. Van Langenhove, Heterogeneous photocatalysis as an advanced oxidation process for the abatement of chlorinated, monocyclic aromatic and sulfurous volatile organic compounds in air: State of the art, Crit. Rev. Environ. Scie. Technol. 37 (2007) 489-538.

[7] S. Malato, P. Fernández-Ibáñez, M.I. Maldonado, J. Blanco, W. Gernjak, Decontamination and disinfection of water by solar photocatalysis: Recent overview and trends, Cat. Today 147 (2009) 1-59.

[8] I. Oller, S. Malato, J.A. Sánchez-Pérez, Combination of Advanced Oxidation Processes and biological treatments for wastewater decontamination-A review, Sci. Total Environ. 409 (2011) 4141-4166.

[9] G.P. Anipsitakis, E. Stathatos, D.D. Dionysiou, Heterogeneous Activation of Oxone Using Co3O4, J. Phys. Chem. B 109 (2005) 13052-13055.

[10] P. Hu, M. Long, Cobalt-catalyzed sulfate radical-based advanced oxidation: A review on heterogeneous catalysts and applications, Appl. Catal. B. Environ. 181 (2016) 103-117.

[11] F. Ghanbari, M. Moradi, Application of peroxymonosulfate and its activation methods for degradation of environmental organic pollutants: Review, Chem. Eng. J., 310 (2017) 41-62.

[12] Council Directive 98/83/EC of 3 November 1998 on the quality of water intended for human consumption.

[13] S. Navalon, M. Alvaro, H. Garcia, Heterogeneous Fenton catalysts based on clays, silicas and zeolites, Appl. Catal. B-Environ 99 (2010) 1-26.

[14] S. Navalon, A. Dhakshinamoorthy, M. Alvaro, H. Garcia, Heterogeneous Fenton catalysts based on activated carbon and related materials, ChemSusChem 4 (2011) 1712-1730.

[15] E.G. Garrido-Ramírez, B.K.G. Theng, M.L. Mora, Clays and oxide minerals as catalysts and nanocatalysts in Fenton-like reactions - A review, Appl. Clay Sci. 47 (2010) 182-192.

[16] Q. Yang, H. Choi, S.R. Al-Abed, D.D. Dionysiou, Iron-cobalt mixed oxide nanocatalysts: heterogeneous peroxymonosulfate activation, cobalt leaching, and ferromagnetic properties for environmental applications, Appl. Catal. B. Environ. 88 (2009) 462-469.

[17] P. Shukla, H. Sun, S. Wang, H.M. Ang, M.O. Tadé, Nanosized Co3O4/SiO2 for heterogeneous oxidation of phenolic contaminants in waste water, Separ. Purif. Technol. 77 (2011) 230-236. 
[18] Q. Yang, H. Choi, Y. Chen, D.D. Dionysiou, Heterogeneous activation of peroxymonosulfate by supported cobalt catalysts for the degradation of 2,4dichlorophenol in water: The effect of support, cobalt precursor, and UV radiation, Appl. Catal. B. Environ. 77 (2008) 300-307.

[19] Q.J. Yang, H. Choi, D.D. Dionysiou, Nanocrystalline cobalt oxide immobilized on titanium dioxide nanoparticles for the heterogeneous activation of peroxymonosulfate, Appl. Catal. B. Environ. 74 (2007) 170-178.

[20] P.R. Shukla, S. Wang, H. Sun, H.M. Ang, M. Tadé, Activated carbon supported cobalt catalysts for advanced oxidation of organic contaminants in aqueous solution, Appl. Catal. B. Environ. 100 (2010) 529-534.

[21] Y. Hardjono, H. Sun, H. Tian, C.E. Buckley, S. Wang, Synthesis of Co oxide doped carbon aerogel catalyst and catalytic performance in heterogeneous oxidation of phenol in water, Chem. Eng. J. 174 (2011) 376-382.

[22] P.R. Shukla, S.B. Wang, K. Singh, H.M. Ang, M.O. Tade, Cobalt exchanged zeolites for heterogeneous catalytic oxidation of phenol in the presence of peroxymonosulphate,, Appl. Catal. B. Environ. 99 (2010) 163-169.

[23] K.-Y. Andrew Lin, H.-A. Chang, Zeolitic Imidazole Framework-67 (ZIF-67) as a heterogeneous catalyst to activate peroxymonosulfate for degradation of Rhodamine B in water, J. Taiwan Inst. Chem. Eng., 53 (2015) 40-45.

[24] A. Dhakshinamoorthy, S. Navalon, M. Alvaro, H. Garcia, Metal nanoparticles as heterogeneous fenton catalyst, ChemSusChem 5 (2012) 46-64.

[25] K. Takahashi, S. Yokoyama, T. Matsumoto, J.L.C. Huaman, H. Kaneko, J.-Y. Piquemal, H. Miyamura, J. Balachandran, Towards a designed synthesis of metallic nanoparticles in polyols - elucidation of the redox scheme in a cobaltethylene glycol system, New J. Chem. 40 (2016) 8632--8642.

[26] C. López-Santos, F. Yubero, J. Cotrino, A.R. González-Elipe, Lateral and in-depth distribution of functional groups on diamond-like carbon after oxygen plasma treatments, Diamond and Related Materials, 20 (2011) 49-56.

[27] S. Wacławek, K. Grübel, M. Cerník, Simple spectrophotometric determination of monopersulfate, Spectrochim. Acta A 149 (2015) 928-933.

[28] L. Fan, C. Moreno-Castilla, M.A. Ferro-Garcia, J.P. Joly, I. Bautista-Toledo, F. Carrasco-Marin, J. Rivera-Utrilla, Surface Modifications by Nitric Acid, Hydrogen Peroxide, and Ammonium Peroxydisulfate Treatments Activated Carbon Langmuir, 11 (1995) 4386-4392

[29] M.S. Shafeeyan, W.M.A.W. Daud, A. Houshmand, S. A., A review on surface modification of activated carbon for carbon dioxide adsorption, J. Anal. Appl. Pyrol. 89 (2010) 143-151.

[30] D. Sempere, S. Navalon, M. Dančíková, M. Alvaro, H. Garcia, Influence of pretreatments on commercial diamond nanoparticles on the photocatalytic activity of supported gold nanoparticles under natural Sunlight irradiation Appl. Catal. B-Environ. 142-143 (2013) 259-267.

[31] N. Shimodaira, A. Masui, Raman spectroscopic investigations of activated carbon materials, J. Appl. Phys. 92 (2002) 902-909.

[32] J.-H. Zhou, Z.-J. Sui, J. Zhu, P. Li, D. Chen, Y.-C. Dai, W.-K. Yuan, Characterization of surface oxygen complexes on carbon nanofibers by TPD, XPS and FT-IR, Carbon 45 (2007) 785-796.

[33] B.S. Girgis, Y.M. Temerk, M.M. Gadelrab, I.D. Abdullah, X-ray Diffraction Patterns of Activated Carbons Prepared under Various Conditions, Carbon Sci. 2 (2007) 95-100. 
[34] J.C. Espinosa, S. Navalón, M. Álvaro, H. García, Copper nanoparticles supported on diamond nanoparticles as a cost-effective and efficient catalyst for natural sunlight assisted Fenton reaction, Catal. Sci. Technol. 6 (2016) 7077-7085.

[35] R. Shi, G. Chen, W. Ma, D. Zhang, G. Qiu, X. Liu, Shape-controlled synthesis and characterization of cobalt oxides hollow spheres and octahedra, Dalton Trans. 41 (2012) 5981-5987.

[36] J. González-Prior, R. López-Fonseca, J.I. Gutiérrez-Ortiz, B. de Rivas, Oxidation of 1,2-dichloroethane over nanocube-shaped Co3O4 catalysts, Appl. Catal. B. Environ. 199 (2016) 384-393.

[37] W. Guo, Y. E, l. Gao, L. Fan, S. Yang, A catalytic nanostructured cobalt oxide electrode enables positive potential operation for the cathodic electrogenerated chemiluminescence of Ru(bpy)32+ with dramatically enhanced intensity Chem.Commun. 46 (2010) 1290-1292.

[38] H.M. Chen, R.-S. Liu, H. Li, H.C. Zeng, Generating isotropic superparamagnetic interconnectivity for the two-dimensional organization of nanostructured building blocks, Angew. Chem. Int. Ed. 45 (2006) 2713 -2717.

[39] A. Dhakshinamoorthy, S. Navalon, D. Sempere, M. Alvaro, H. Garcia, Aerobic oxidation of thiols catalyzed by copper nanoparticles supported on diamond nanoparticles, ChemCatChem 5 (2013) 241-246.

[40] I.H. Kim, H.O. Seo, E.J. Park, S.W. Han, Y.D. Kim, Low temperature CO oxidation over iron oxide nanoparticles decorating internal structures of a mesoporous alumina, Sci. Rep. 7 (2017) 40497.

[41] H. Sun, H. Liang, G. Zhou, S. Wang, Supported cobalt catalysts by one-pot aqueous combustion synthesis for catalytic phenol degradation, J. Colloid Interf. Sci. 394 (2013) 394-400.

[42] S. Navalon, A. Dhakshinamoorthy, M. Alvaro, H. Garcia, Metal nanoparticles supported on two-dimensional graphenes as heterogeneous catalysts, Coord. Chem. Rev. 312 (2016) 99-148

[43] K.-Y. Andrew Lin, W.-C. Tong, Y. Du, Cobalt-embedded carbon nanofiber derived from a coordination polymer as a highly efficient heterogeneous catalyst for activating oxone in water, Chemosphere 195 (2008) 272-281.

[44] J. Sun, X. Li, J. Feng, X. Tian, Oxone/Co2+ oxidation as an advanced oxidation process: comparison with traditional Fenton oxidation for treatment of landfill leachate. , Water Res. 43 (2009) 4363-4369.

[45] D.L. Ball, J.O. Edwards, The Kinetics and Mechanism of the Decomposition of Caro's Acid. J. Am. Chem. Soc., 78 (1956) 1125-1129.

[46] W. Guo, S. Su, C. Yi, Z. Ma, Degradation of antibiotics amoxicillin by Co3O4catalyzed peroxymonosulfate system. , Environ. Prog. Sustain. Energy 32 (2013) 193-197.

[47] H. Sun, H. Tian, Y. Hardjono, C.E. Buckley, S. Wang, Preparation of cobalt/carbon-xerogel for heterogeneous oxidation of phenol, Catal. Today 186 (2012) 63-68.

[48] Y. Wang, H. Sun, H.M. Ang, M.O. Tadé, S. Wang, Facile Synthesis of Hierarchically Structured Magnetic MnO2/ZnFe2O4 Hybrid Materials and Their Performance in Heterogeneous Activation of Peroxymonosulfate, ACS Appl. Mater. Interfaces 6 (2014) 19914-19923.

[49] G.P. Anipsitakis, D.D. Dionysiou, Radical generation by the interaction of transition metals with common oxidants, Environ. Sci. Technol. 38 (2004) 37053712. 
[50] S.K. Ling, S. Wang, Y. Peng, Oxidative degradation of dyes in water using Co2+/H2O2 and Co2+/peroxymonosulfate, J. Hazard. Mater. 178 (2010) 385389.

[51] P. Shukla, H. Sun, S. Wang, H.M. Ang, M.O. Tadé, Co-SBA-15 for heterogeneous oxidation of phenol with sulfate radical for wastewater treatment, Catal. Today 175 (2011) 380-385.

[52] Y. Wang, H. Sun, H.M. Ang, M.O. O. Tadé, S. Wang, 3D-hierarchically structured $\mathrm{MnO} 2$ for catalytic oxidation of phenolsolutions by activation of peroxymonosulfate: Structure dependenceand mechanism, Appl. Catal. B. Environ. 164 (2015) 159-167.

[53] S.B. Hammoudaa, F. Zhaoa, Z. Safaeia, V. Srivastavaa, D.L. Ramasamya, S.I. Iftekhara, S. kalliola, M. Sillanpää, Degradation and mineralization of phenol in aqueous medium by heterogeneous monopersulfate activation on nanostructured cobalt based-perovskite catalysts ACoO3 (A = La, Ba, Sr and Ce):

Characterization, kinetics and mechanism study, Appl. Catal. B. Environ. 215 (2017) 60-73.

[54] G. Zhou, L. Zhou, H. Sun, H.M. Ming Ang, M.O. Tadé, S. Wang, Carbon microspheres supported cobalt catalysts forphenol oxidation with peroxymonosulfate, Chem. Eng. Res. Des. 101 (2015) 15-21.

[55] S. Muhammad, E. Saputra, H. Sun, H.-M. Ang, M.O. O. Tadé, S. Wang, Heterogeneous Catalytic Oxidation of Aqueous Phenol on Red Mud-Supported Cobalt Catalysts, Ind. Eng. Chem. Res. 51 (2012) 15351-15359.

[56] A. Rastogi, S.R. Al-Abed, D.D. Dionysiou, Sulfate radical-based ferrouseperoxymonosulfate oxidative system for PCBs degradation in aqueous and sediment systems, Appl. Catal. B 85 (2009) 171-179. 